\title{
Influenza morbidity and mortality in Kerala: Hotspots that go unnoticed
}

\section{Prabin Pradeep, Vidya Manju, Sathish Mundayoor and Mohammad Feraz Ahsan*}

Centre for Communicable Diseases, Control and Prevention (Viral Research and Diagnostic Centre), Inter University Centre for Biomedical Research and Super Speciality Hospital, Kerala, India

*Corresponding Author: Mohammad Feraz Ahsan, Centre for Communicable Diseases, Control and Prevention (Viral Research and Diagnostic Centre), Inter University Centre for Biomedical Research and Super Speciality Hospital, Kerala, India. E-mail: feraz.niv@gmail.com
Received: February 17, 2020

Published: March 10, 2020

(C) All rights are reserved by Mohammad

Feraz Ahsan., et al.

\begin{abstract}
Influenza viruses are a major health challenge faced by the global society; with the need for new vaccine every year and also the surfacing of antiviral resistance. Kerala has witnessed the occurrence of some zoonotic diseases in the past; there is presence of influenza A virus H1N1 in the state, but there is no proper data on any subtypes other than H1N1 from Kerala. The state is ecologically rich in forests, lakes, rivers and wildlife, resulting in mingling of many different species of animals and birds. Humans are at potential risk of getting infected from zoonotic viruses' transmitted from the animal reservoir. This review tries to create a systemic data from the available data source on the presence of influenza virus in Kerala, also the status of the fauna of the state to identify the possible hotspots of viral spillover.
\end{abstract}

Keywords: Influenza Virus; Epidemiology; Kerala; Zoonotic Diseases; H1N1; Swine Flu

\section{Abbreviations}

HA: Hemagglutinin; NA: Neuraminidase; RNA: Ribonucleic Acid; PB1: Polymerase Basic 1; PB2: Polymerase Basic 2; PA: Polymerase Acidic; NP: Nucleoprotein; M1: Matrix 1; M2: Matrix 2; RDRP: RNA Dependent RNA Polymerase; vRNA: Viral RNA; GTP: Guanosine-5'Triphosphate; Eif4e: Eukaryotic Translation Initiation Factor 4E; NLS: Nuclear Localization Signal; cRNA: Complementary RNA; vRNPS: Viral Ribonucleoprotein; HEF: Hemagglutinin-Esterase-Fusion; NS1: Non-Structural Protein 1; NS2: Non-Structural Protein 2; MRNA: Messenger RNA; PI3K: Phosphoinositide 3-Kinase; NEP: Nuclear Export Protein; Crm1: Chromosomal Maintenance 1; CDC: Centers For Disease Control And Prevention; WHO: World Health Organization; OIE: World Organisation For Animal Health (Office International Des Epizooties); FAO: Food And Agriculture Organization; LPAI: Low Pathogenic Avian Influenza Virus; HPAI: High Pathogenic Avian Influenza Virus; ELISA: Enzyme-Linked Immunosorbent Assay; EFL: Ecologically Fragile Land; DHS: Directorate Of Health Services; NCDC: National Centre For Disease Control; JEV:
Japanese Encephalitis Virus; CHPV: Chandipura Virus; KFD: Kyasanur Forest Disease

\section{Introduction}

Influenza viruses belong to the family Orthomyxoviridae and have type A, B, C, and D based on their genome [1]. Other viruses belonging to this family are Isavirus, Thogotovirus and Quaranjavirus. Influenza viruses are enveloped, single-stranded negative sense, segmented RNA viruses. Influenza A viruses are classified into subtypes based on their surface glycoprotein hemagglutinin (HA) and neuraminidase (NA). A total of 18 HA (H1 - H18) and 11 NA (N1 - N11) are known to exist in nature [1,2].

\section{Viral structure}

Influenza A viruses contain a total of 8 RNA segments which codes for 12 - 14 proteins depending on various strains (Figure 1). Influenza B virus also contains 8 RNA segments but they code for only 11 proteins (Figure 2). Whereas influenza $C$ and D viruses contain only 7 RNA segments encoding 9 proteins [1] (Figure 3). 


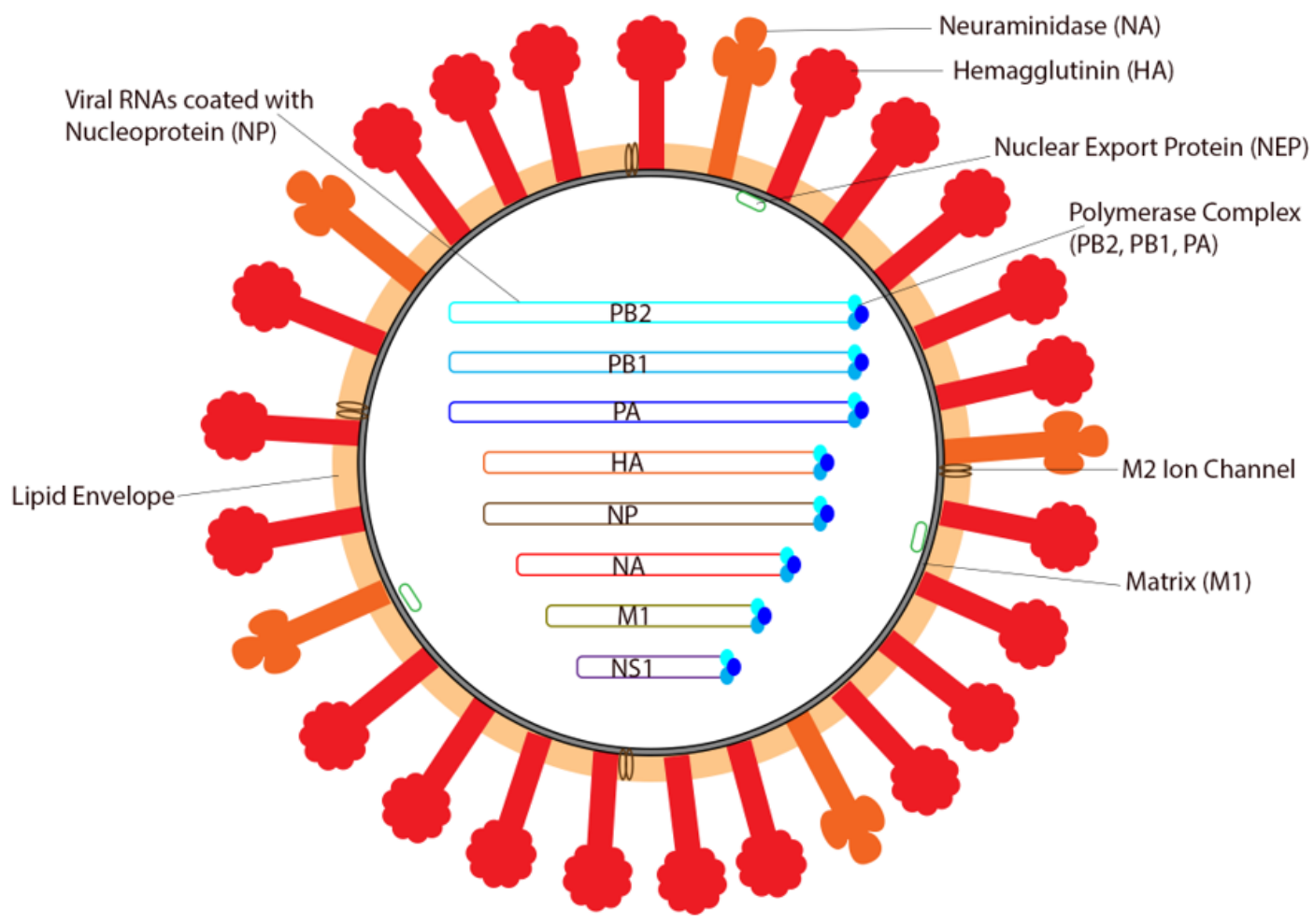

Figure 1: Influenza A virus structure.

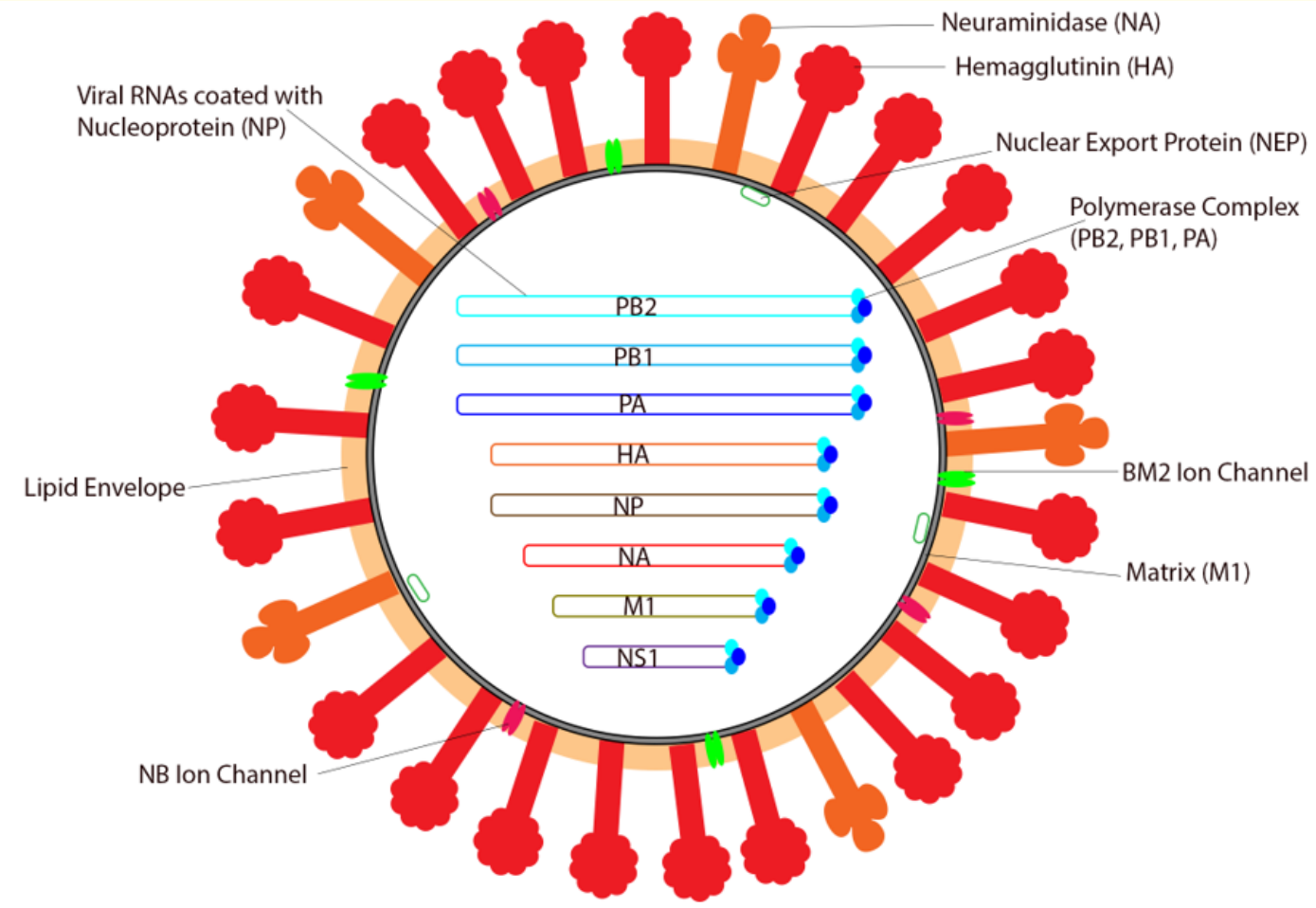

Figure 2: Influenza B virus structure. 


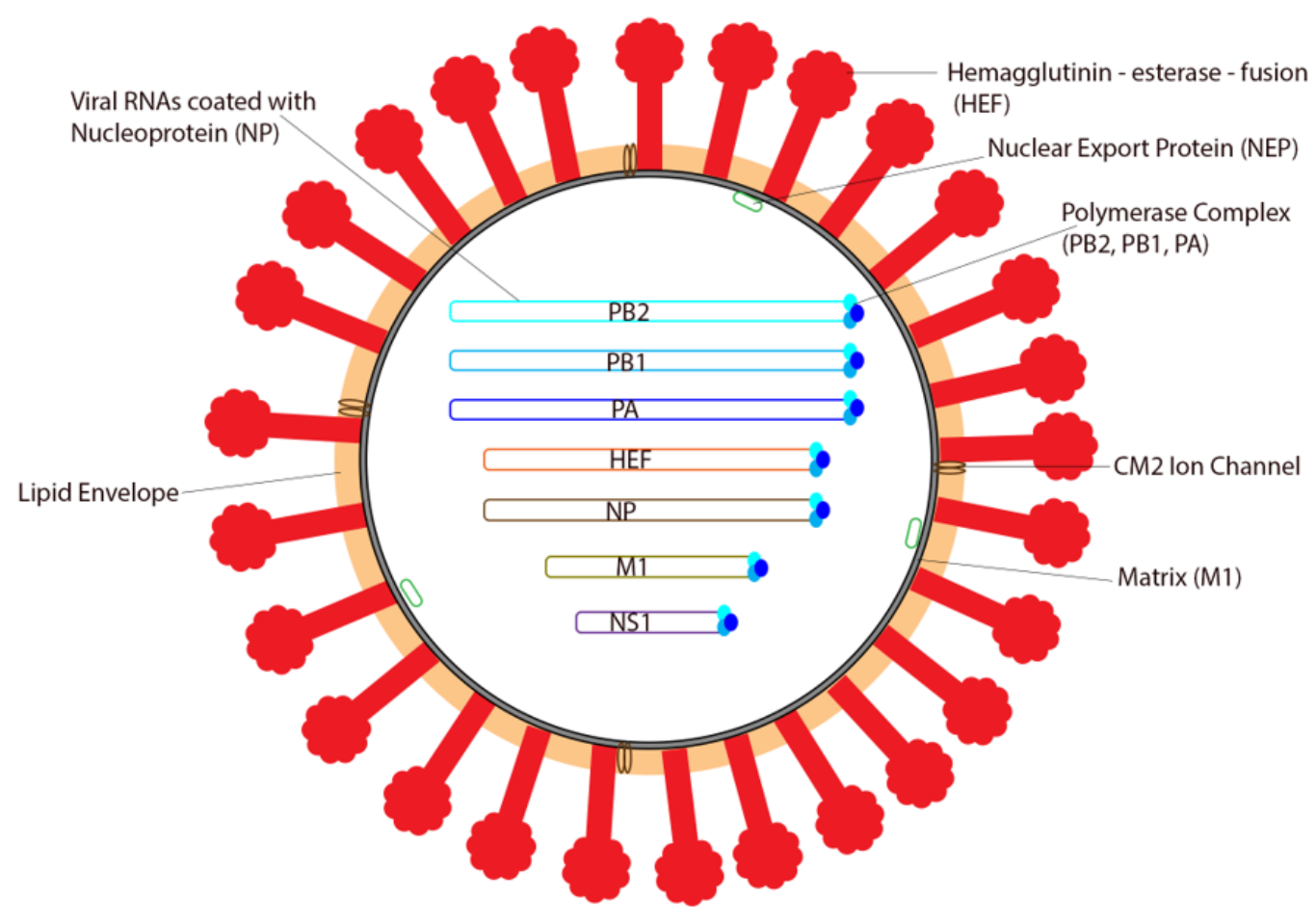

Figure 3: Influenza C and D virus structure.

Viral polymerase complex

\section{PB1 (polymerase basic 1)}

The catalytic site of influenza RNA polymerase is the PB1 subunit, which contains conserved sequence motifs that are present in a viral RdRp (RNA dependent RNA polymerase). Mutation of conserved motifs inactivates the RNA synthesis activity of the polymerase. The PB1 interacts with both PA and PB2 subunits in the $\mathrm{N}$-terminal and C-terminal regions respectively [1], for the successful completion of viral replication.

\section{PB2 (polymerase basic 2)}

The PB2 protein of the influenza virus is responsible for the initiation of transcription by binding to the cap on the pre-mRNA molecules of the host cell to snatch the 5 ' cap for the replication of vRNA (Viral RNA). The residues 318-483 were identified as playing an important role in the cap-binding mechanism, which is also bound to 5' - cap analogue (m7GTP). It shows common features, which are similar to already known cap-binding proteins such as eIF4E and vaccinia virus VP39. The C-terminal of PB2 contains a bipartite NLS (Nuclear Localization Signal) sequence which is required for the import of the PB2 into the nucleus of the cell. The extended C-terminal fragment of the PB2 has been structurally identified and characterized as an RNA binding domain [1].

\section{PA (polymerase acidic)}

The PA subunit of the influenza A virus has a generalized proteolytic activity. The $\mathrm{N}$ terminal of the PA subunit has the endonuclease activity and plays a critical role rather than the previous conceptions of PB1 having endonuclease activity. It also plays a major role in the promoter binding of vRNA and cRNA (complementary RNA) of the influenza virus [1].

\section{Hemagglutinin (HA)}

HA is the major surface protein of influenza viruses. It plays a major role in receptor binding of the virus to the cell and pH-mediated fusion of the viral membrane. The hemagglutinin of the influenza virus is a trimeric molecule of which the carboxy-terminal is inserted into the membrane of the virus, while the hydrophilic end forms a spike which is away from the viral membrane. The structure and function of the HA molecules are highly conserved among the different HA subtypes even though they only have less than 50\% sequence similarity. Similarly, the HA of influenza A and B virus show only $\sim 25 \%$ sequence similarity, still structurally simi$\operatorname{lar}[1]$.

The HA of influenza virus is cleaved into HA1 and HA2, which are linked together through a disulphide bond. Out of the two, HA1 contains the sialic acid binding site and HA2 is the stalk, the bound 
virus is then internalized into the endosome. It is followed by a conformational change in the HA triggered by the $\mathrm{pH}$ change in the endosome. This results in the loop-to-helix transition of $\mathrm{HA}$ allowing HA2 to attach to the endosomal membrane, which in turn promotes the fusion of the viral membrane to the endosomal membrane resulting in the release of the vRNPs (viral ribonucleoprotein) into the cytoplasm of the cell [1].

Whereas in influenza $\mathrm{C}$ virus they contain a different glycoprotein named HEF (Hemagglutinin-esterase-fusion) which has the activity of both hemagglutinin and neuraminidase. The HEF contains an esterase activity which cleaves of the sialic acid receptor while the release of influenza $C$ virus from the infected cell [1].

\section{Nucleoprotein (NP)}

The RNA of the influenza virus is always coated by the NP and they never exist as naked RNA. In influenza A virus the NP is a polypeptide of 498 amino acids, while in influenza $B$ and $C$ viruses the length of the polypeptide is of 560 and 565 amino acids respectively. The NP protein has a net positive charge at neutral $\mathrm{pH}$ and this is said to be the major reason for its interaction with the viral RNA molecules, NP is an arginine, Glycine and Serine-rich protein [1].

Neuraminidase (NA)

The second major glycoprotein after HA in influenza A and B virus is the NA. It is a type II integral protein. The NA is a tetramer which is attached to the viral membrane through a hydrophobic region of the central stalk. The NA plays a major role in the release of the virus from the surface of the cell by removing/cleaving the sialic acid receptor [1].

\section{Matrix proteins}

\section{M1 protein}

It is the most abundant protein in the virus and it binds to the vRNPs and it plays a very important role in stabilizing the 3D structure of the envelope in the whole virion. In addition, M1 plays a key role in the export of vRNPs from the nucleus and in the assembly and budding of the virus, as shown through various experiments [1].

\section{M2 protein}

It is one of the smallest ion channels known to humans. The M2 of influenza A and B form tetrameric proton channels, which open in response to the low $\mathrm{pH}$ in the endosome resulting in the $\mathrm{H}+\mathrm{in}$ flux. These steps lead to the merging of the viral membrane with the endosomal membrane and the disassociation of vRNPs from the viral membrane into the cytoplasm. M2 protein also maintains the high $\mathrm{pH}$ of the Trans-Golgi network so that there is no premature conformational change in HA [1].

\section{Non-structural proteins} NS1

NS1 of influenza virus is known as a multifunctional protein capable of doing various functions through protein-protein interactions and protein-RNA interactions of which some are well studied and characterized, while others are still unknown. But the main function of NS1 is thought to be its ability to suppress interferon activity, hence it is also known as an interferon antagonist. Some of the known important mechanisms of NS1 are regulation of viral RNA synthesis, control of mRNA splicing, enhancement of viral mRNA translation, regulation of virus particle morphogenesis, suppression of host immune/apoptotic responses, activation of PI3K and strain-dependent pathogenesis [1].

NS2

The initial studies suggest that M1 plays a sole role in the export of RNPs to the cytoplasm. But nuclear export of large molecules requires the assistance of cellular export machinery, and there is no evidence suggesting such interaction of M1 with cellular export machinery. NEP/NS2 has demonstrated its interaction with the export receptor $\mathrm{Crm} 1$ and several other nucleoporins. The current data suggests the formation of an RNP-M1-NEP/NS2 complex and NEP/NS2 coupling with nuclear export proteins results in the nuclear exit of RNPs. In influenza C virus NES does the job of NEP/ NS2, composed of two separate leucine-rich domains [1].

\section{Pathology of influenza}

Influenza is an acute respiratory illness indicated by sudden onset of high fever alongside cough, headache, malaise and inflammation of the upper respiratory tract and trachea. In some cases, pneumonia is also seen. A high number of influenza cases are recorded during winters and during sudden outbreaks/epidemics. Severe forms of Influenza are seen in infants, old-aged people and those suffering from other underlying illnesses [3].

Influenza is spread through aerosol and respiratory secretions such as saliva from an infected person. It attaches and multiplies in the epithelial cells of the respiratory tract. The virus has the capability to spread and infect both upper and lower respiratory tract.

\section{Epidemiology}

Influenza virus outbreaks have been recorded since very ancient times with records pointing it to be 500 years old. And records reveal that there have been around 14 or more major pandemics that happened after 1500 excluding the well-known pandemics of 1889 , $1918,1957,1968,1977$ and 2009. 
The gigantic of all is the 1918 Spanish flu which is estimated to have killed 50 million people or more worldwide, and has been described as "The Mother of all pandemics". And it has an unusual severity in young age group compared to other known influenza pandemics. The virus was of avian origin $\mathrm{H} 1 \mathrm{~N} 1[4,5]$.

During the 1957 Asian flu pandemic of H2N2, the death was estimated around to be 2 million. This virus was found to be a reassorted virus having the HA, NA, and PB1 of the avian influenza virus, while the rest of the segments were of the known human influenza virus $[4,5]$.

During 1968 another flu pandemic, Hong Kong flu pandemic emerged with the virus strain being H3N2 type. This new wave was again caused by the reassortment of the already circulating H2N2 virus with another avian influenza virus. This time around another 1 to 4 million people died. This virus is still circulating in humans and also causes sporadic outbreaks $[4,5]$.

The 1977 Russian flu pandemic is the mystery of the century as the virus was similar in every aspect to the H1N1 circulating in 1950, and which just re-emerged after 27 years. How did it stay dormant for 27 years is still not understood? [4].

In 2009 the WHO declared outbreak by another H1N1 virus a triple reassortment virus causing a pandemic and it was elevated to phase 6 pandemic by WHO as it spread throughout the world in a short period of time and also replaced the former H1N1 1918 strain which was circulating earlier. The 2009 pandemic was earlier known as swine flu, but as further research found out that it has swine, bird and human influenza segments. The currently circulating H1N1 outbreaks and seasonal strains are of 2009 H1N1 influenza virus [5].

But still, our understanding of the pandemic potential influenza viruses is very low. The emergence of variants such as H5N1, H7N9 and H9N2 has contributed to the confusion regarding the possibility of the next pandemic. The acquisition of the ability of the viruses to jump the species barrier has increased the need for more extended research.

Other than these outbreaks there are a higher number of outbreaks in avian every year worldwide resulting in the death by infection and culling of millions of birds worldwide. Alongside there is the infection of pigs (Swine Flu), dogs (Canine Flu), cats, tigers, lions and other feline species (Feline Flu), horses (Equine Flu), seals, whales, bats, etc.
Hosts

\section{Human influenza}

Human epidemics caused by influenza A and B results in effects which differ by a huge margin in different individuals, with some having mild cold symptoms to that of severe lung injury resulting in death. The mortality curve associated with the influenza virus is usually U-shaped, owing to high death rates in persons above 65 years of age and children below 2 years. This scenario is true for all influenza outbreaks except in the pandemics of 1918 and 2009 where a W-shaped curve was observed, showing higher mortality rates in younger adults, along with a decreased severity in the elderly, possibly due to the pre-existing immunity [6].

New pandemic arises when novel influenza viruses crop up with the ability to spread and infect the population with ease. For a new virus to emerge and adapt to humans as a new host is either through direct transfer from birds to humans or via further adaptation in an intermediate host like swine. This adaptation is necessary for its successful replication as the avian influenza virus replicates in the gastrointestinal epithelia which predominately expresses $\alpha 2,3$ - linked sialic acid receptors, which is not the case with humans as we express $\alpha 2,6$ - linked sialic acid receptors in our trachea and upper respiratory tract. Therefore for adaptation, the avian influenza virus should mutate its replication machinery to suit the new human host [6].

For the successful attachment of the avian influenza virus to the new human host, it has to mutate its HA for a switch from $\alpha 2,3$ linked sialic acid to $\alpha 2,6$ - linked sialic acid. Same way for the following fusion to take place again, a mutation is necessary for the $\mathrm{HA}$ as it is specific to $\mathrm{pH}$ for conformational change, for a successful fusion without the virus getting deactivated. The $\mathrm{pH}$ requirement of the avian viruses ranges from 5.6 - 6.0, while for their human variants a pH of 5.4 - 5.6 is required. Another important step is the transportation of the viral RNA segments to the nucleus of the cell from the cytoplasm with the help of the importin $\alpha$. The human influenza viruses make use of importin $\alpha 7$ for this; whereas the avian influenza viruses require importin $\alpha 3$, for this switch to take place mutations are required in the NP and PB2 segments. Finally, the release of the virus from the cell requires the action of NA to cleave the sialic acid receptor from the cell surface. For the NA activity to happen, it also needs to switch from $\alpha 2,3$ to $\alpha 2,6$, adaptation to the new $\mathrm{pH}$ and temperature. Therefore, for a species barrier jump from avian to the human requires these mutations to acquire the 
ability to spread from human-human for a pandemic potential virus. While in the past H5, H7 and H9 subtypes of the avian influenza virus has been shown to infect humans, which has not achieved interhuman transmissibility [7].

\section{Avian influenza}

Avian influenza virus is highly contagious for birds and is caused by the group of influenza A viruses. The host reservoir species for the virus are aquatic birds including gulls, terns, and shorebirds, waterfowl including ducks, geese, and swans worldwide, but incidentally, they may infect other avian species including domestic poultry or even some mammalian species including humans. Influenza A viruses infect and replicate in the respiratory tract and intestines of several wild aquatic birds without causing illness., But these viruses are highly contagious and cause mortality in most of the other species of birds especially domesticated poultry such as chickens, ducks and turkeys. Transmission among birds is through infected saliva, nasal secretions, faeces and also through contact with infected surfaces such as egg flats, feed trucks and poultry workers. There is also a possibility of vertical transmission with the virus being isolated from yolk and albumin of eggs from infected birds. But it is unlikely that such an infected egg could survive the infection and hatch to carry virus forward. The incubation of the influenza virus in birds varies from 3 to 5 days to a maximum of 21 days in some cases [8].

Based on the disease severity in birds, the avian influenza virus is classified into two; one is low pathogenic avian influenza virus (LPAI), as the name suggests it causes very mild illness or no illness based on the bird species. The other category is called highly pathogenic avian influenza virus (HPAI), which has the capability to cause severe illness and has a high mortality. The only subtypes recorded to cause HPAI in birds are H5 and H7. Between the periods of January 2005 to December 2012 (Termed as previous panzootic by Office International des Epizooties (OIE)) a total of 8,345 HPAI outbreaks were reported from 65 countries caused by 4 different subtypes. The current panzootic ongoing since January 2013 (data till August 2019) has reported a total of 7,122 outbreaks in 68 countries caused by 12 different subtypes. Thus, this is a huge increase in the circulating subtypes compared to the previous panzootic. The current circulating subtypes around the globe are H5N1, H5N2, H5N3, H5N5, H5N6, H5N8, H5N9, H7N2, H7N3, H7N7, H7N8, and H7N9 [8].
The infections caused by H5N1 created waves of fear for a possible new emerging influenza pandemic in the world, as it contained a completely new type of HA and NA to which the human population is not immune. Even after more than 15 years of infection by H5N1 in humans, the virus has not shown potent transmission from human to humans and as a result, most infections in man are for those who come in direct contact with the infected birds. But the fact that it has a $60 \%$ mortality rate, and is slowly but steadily adapting to the human population suggests that it could be a future threat. But the sudden rise in infection by $\mathrm{H} 7$ and H9 subtypes in humans is leading to new challenges to the human population. The total number of confirmed H5N1 cases in humans are 861 with 455 reported deaths from 2003 to 2019. While the cumulative number of human infections of H7N9 reported to WHO are 1567 with at least 615 deaths $[9,10]$.

As per the reports of OIE a total loss of 122 million domesticated birds were reported due to HPAI during this current panzootic till $31^{\text {st }}$ August 2018.

\section{Swine influenza}

The circulation of influenza virus in the swine population is rampant, even though severe diseases are rare. The first isolation of influenza virus from pigs was carried out in 1930 by Shope and demonstrated that it causes a respiratory disease similar to that of human influenza [11]. Common subtypes of influenza virus in swine are H1N1, H1N2 and H3N2. Other subtypes such as H3N1 and H2N3 are also detected in swine, while H2N3 has not yet established in the swine population. The virus is transmitted from pig to pig through contact such as nose to nose contact or through direct contact of mucus. Nasal secretions as aerosol/droplets also shed the virus [12].

Reverse zoonosis events, where the virus is spillover from humans, happens in case of influenza, which resulted in the spread of H1N1pdm09 in countries like Australia and Norway which were considered free of swine influenza virus. As swine is susceptible to both human and avian influenza viruses, sporadic introductions of both viruses are reported in the swine population. While many of this spillover virus fail to establish themselves in the swine for a long duration, both human H1N1 and H3N2 viruses are reported in the swine. Avian subtypes H5N1, H9N2, H1N1, H3N2, H5N2, H6N6, H7N2, H4N8 and H11N6 have been reported in the swine from different parts of the world. Other types are from equine origin H3N8 
and H1N7 of human and equine origin in China and Great Britain respectively [13].

Except for some viruses like H2N3 in the USA most avian viruses do not transmit widely in the swine population. Swine is theorized as the "mixing vessel" of the influenza viruses. And this makes swine a medium for recombination and the formation of a completely new combination of influenza viruses. The best examples are the 1957 Hong Kong flu and the 1967 Asian flu, which were caused by the antigenic shift between human and avian influenza viruses. The 1918 Spanish flu was caused by an influenza virus transferred from pigs, so is the 2009 pandemic from a triple reassorted virus from pigs [14].

\section{Feline influenza}

Influenza viruses have the ability to infect cats including avian influenza and such virus has the capability to spread from one cat to the other same way as human influenza. It can be through direct contact such as licking, sleeping and playing together, nuzzling, through air droplets created by coughing, sneezing, nasal discharges and through contaminated surfaces such as food and water bowls, cage surfaces. Even though humans can infect the cats with the virus, it is still not properly understood whether the reverse takes place [15].

The first reported feline influenza outbreak is of pH1N1 in a cat colony in Italy (2009), where the virus was isolated from the lung homogenates of two dead cats. Serum samples and pharyngeal swabs from 38 of the 90 cats tested by ELISA for antibodies confirmed that 21 of the cats were positive for viral antibodies, while two swabs contained pH1N1 RNA. During December 2016 - February 2017 approximately 500 cats were infected by avian influenza H7N2 subtype in animal shelters in New York. During this outbreak, the first reported spread of the virus from cat to human was also recorded in a veterinarian treating the cats $[16,17]$.

\section{Canine influenza}

Canine influenza or dog flu is caused by two subtypes of influenza virus H3N8 and H3N2. Canine flu is spread through air droplets caused by coughing or sneezing or by contact with contaminated surfaces. The canine influenza A(H3N2) is different from that of the commonly circulating seasonal influenza A(H3N2) in humans. Canine influenza viruses can also spread to cats and cause illness. Canine influenza viruses are considered to be of low threat to human health [18]. Canine influenza H3N2 viruses spread to dogs from birds and got adapted to dogs. It was first reported in dogs in South Korea (2007), even though there was a report of H3N2 circulating in dogs in China during 2006 and presence of serological evidence of canine influenza H3N2 in South Korea (2005). The canine influenza H3N2 is now reported from South Korea, China, Thailand, Canada and the USA $[19,20]$. These Influenza viruses tend to infect wild canine also such as leopards and tigers as well.

The equine influenza virus H3N8 jumped species and adapted to dogs and this adapted virus spread between dogs. The first reports were from 2004 in greyhounds in Florida, USA, but some studies showed the presence of canine and equine influenza H3N8 as early as 1999 itself [21].

Equine influenza

Equine influenza is a highly contagious respiratory disease infecting horses with almost world-wide distribution. The virus is spread through aerosol transmission. But the distance that the equine influenza virus aerosol can travel is still a controversial topic with claims of 1-2 km, but the most accepted figure is around 35 meters. Equine influenza virus infection in horses is caused by H3N8 and H7N7 subtypes [22].

The first isolation of H7N7 from horses in Europe was reported in 1956. Historical records show equine influenza virus-like equine respiratory disease outbreaks since the 13th century. Repeated outbreaks of equine influenza virus in different parts of the world are from USA and Canada in 1963, Japan in 1971, Malaysia in 1977, UK in 1979, South Africa in 1986, India in 1987, UK and China in 1989, Nigeria in 1991, Hong Kong in 1992, USA in 2004, Australia in 2007, India and Central Asia in 2011-2012. But the 1872 outbreak is considered to be the largest recorded equine influenza virus epizootic in North America snubbed "The Great Epizootic of 1872" [22].

Influenza is endemic in horses in most part of the world except New Zealand and Iceland. During the period of 2006-2017 China, France, Germany, Ireland, Malaysia, Sweden, UK, USA, Japan, India, Russia, Brazil all had a minimum of one equine influenza outbreak [22].

\section{Others}

The New England coast of the USA reported the first confirmed outbreak of influenza A virus H7N7 between December 1979 and October 1980 followed by outbreaks of H4N5, H4N6, H3N3 during 
1982, 1991 and 1992 respectively. Harbour seals and Grey seals can also be infected by influenza B virus as demonstrated by the presence of antibodies. The mass death of harbour seals in Europe (Germany, Denmark and Sweden) during 2014 was confirmed to be caused by avian influenza A virus H10N7. Samples of New England harbour seals that died due to an outbreak of pneumonia in 2011 showed the presence of H3N8 influenza A virus. H5N8 influenza A virus was confirmed in two dead grey seals in November 2016 and April 2017 [23,24].

Tong., et al. 2012 first identified influenza A virus in fruit bats of Guatemala and designated it as H17N11 as both HA and NA were distinct from other identified viruses. This was followed by the identification of influenza A virus H18N11 from flat-faced fruit bats in Peru. H18N11 was later isolated from 2 great fruit-eating bats in Brazil [2,25]. From 1979 to 1983 several epizootics of influenza A virus H1N1 infections were reported in camels in Mongolia. Two studies during 1985 and 1989 reported the presence of antibodies against influenza A viruses in camels from different African countries. During 2012 - 2013 influenza A virus H3N8 was isolated from the Bactrian camels in Mongolia. A study conducted during 2017 - 2018 in Saudi Arabia also reports the presence of influenza H1N1 virus in the camels imported from Sudan and Djibouti. The presence of newly identified influenza D virus from dromedary camels was reported from Ethiopia [26,27].

The first reported outbreaks of cattle influenza virus date back to 1949 in Japan, but there was no influenza virus isolates available from these outbreaks [28]. During the 1970s and 1980s, many recorded cattle influenza outbreaks coincided with the human influenza outbreaks, also a few cattle influenza A virus were isolated from Europe and Russia. A study conducted in the cattle population of the United States with respiratory diseases during 2016 - 2018 identified the presence of influenza C virus. During 2011 influenza virus from pigs was isolated, which was prominent in cattle population and infected pigs which were later characterised as influenza D virus. Later in 2018 Ireland reported the presence of influenza D virus in cattle in the sample collected during 2014 - 2016. Another study in the cattle from slaughterhouses in Ireland reported a seroprevalence of $94.6 \%$ influenza D virus antibodies in the cattle population [29]. A study using 27 goats and 472 sheep serum samples from different states in America during 2014 reported that 7 goat serums out of 27 were positive for influ- enza D virus, while out of 472 sheep 29 were also positive for influenza D virus. Another study on the presence of influenza D virus in animals in China using 607 Samples (230 nasal swabs, 324 serum samples, 45 swine lung sample and 8 goat rectal swabs) from goats, buffalo, pigs and farmed cattle; from the 230 nasal swabs 20 of 156 dairy cattle, 4 of 55 native yellow cattle, 7 of 19 pigs, were found positive for influenza D virus. While from the 324 serum samples 15 of 193 dairy cattle, 3 of 51 buffalo, 27 of 80 goats were positive for influenza D virus. While in 45 swine lung samples 13 showed positive for influenza D virus and 1 of 8 goat rectal swab showed influenza D virus positivity [30].

Lung samples collected from striped whales in Russia during 1976 showed positive to influenza A virus. Whereas post-mortem examination of a pilot whale showed the presence of two influenza virus subtypes from samples of disrupted lung and hilar nodes, which were identified as H13N2 and H13N9 [31,32]. 730 serum samples were collected from wild raccoons in California, Texas, Louisiana, Wyoming and Colorado of which 17 showed an antibody response to avian influenza viruses H10N7, H4N6, H4N2, H3, and H1. Earlier avian influenza virus H4N6 was also isolated from one raccoon. Influenza virus $\mathrm{H} 5 \mathrm{~N} 1$ was reported in wild raccoons in Japan [33,34]. Giant pandas were infected by pandemic H1N1 in China in 2009, while few pandas showed reactivity to H3 and H6 subtypes of influenza virus [35]. In 2018 again an infection with human pandemic H1N1 virus was seen in giant panda captive at Ocean Park, Hong Kong [36]. During 2014 at Smithsonian's national zoo in the United States, a hand-reared sloth bear having respiratory problems showed H1N1 positivity, the virus was successfully isolated from the sloth bear [37].

\section{Kerala: A bird's eye view}

Kerala is the southwestern state of India, which is popularly known as the "God's own country" for its natural charm and beauty. The mountain range of Western Ghats spans the eastern side of Kerala, the coastline of Arabian Sea on the western side, with a unique network of many rivers, lake, canals and backwater (Figure 4) throughout. Kerala constitutes 1 per cent of the Indian subcontinent with 38,863 sq. $\mathrm{km}$. Kerala is an ecologically rich state with forests, lakes, rivers and wildlife in abundance. It has nearly $11,309.48 \mathrm{sq}$. $\mathrm{km}$ of forest, with 44 rivers with about a total length of $3504 \mathrm{~km}$ altogether. There are about 89 mountains in Kerala with heights ranging from $1500 \mathrm{ft}$ to $8841 \mathrm{ft}$. It is roughly divided into three geographical regions, namely highlands, midlands and 
wildlands. Highlands are mostly consisting of the Western Ghats. While midlands are made of mesmerizing valleys, the coastline consists of quaint backwaters, further interconnected by canals and rivers flowing from the undulating hills. The wildlands consist of mostly of vivid green dense forests areas, tea and coffee plantations and other cultivations [38].

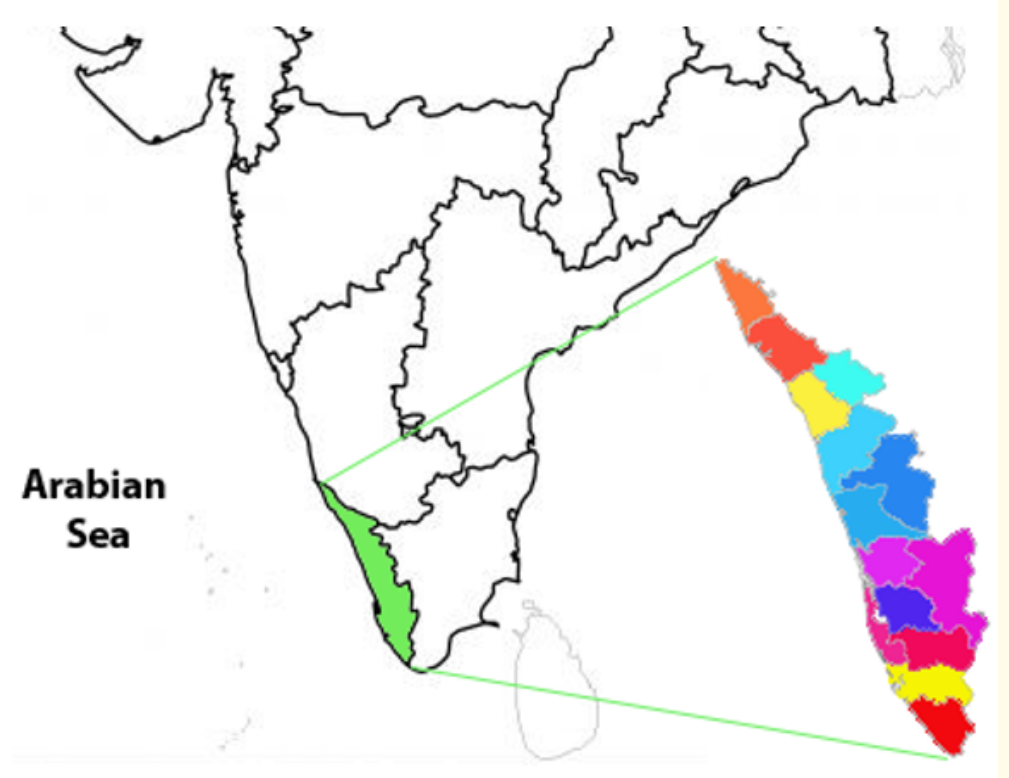

Figure 4: Map showing location of Kerala.

Kerala has three types of seasons, southwest monsoon during the months of June, July, August and September (JJAS), Northeast monsoon during October, November, December (OND), and summer during March, April, May (MAM). The winter season in the months of December and February in Kerala is not noted like other states of India. The climate of Kerala is roughly characterised into mild winds and rapid monsoon showers. Kerala as a state has two monsoons with a varying rainfall from 2000 to that of 2017 with lowest being $1870.9 \mathrm{~mm}$ of annual rain in 2016 to a highest of $3489.6 \mathrm{~mm}$ in 2007 . The chart showing the variation is shown in figure 5. As per the 2011 census report, Kerala has an approximate population of 3.34 Crores $(33,406,061)$. The male population of the state is $16,027,412$ and the female population is $17,378,649$ with a sex ratio of 1084 females in 1000 males (Figure 6 and 7). The population density of Kerala is estimated to be $860 / \mathrm{sq} . \mathrm{km}$. and about $1.45 \%$ is the tribal population which stands at 4,84,839 (Figure 8).

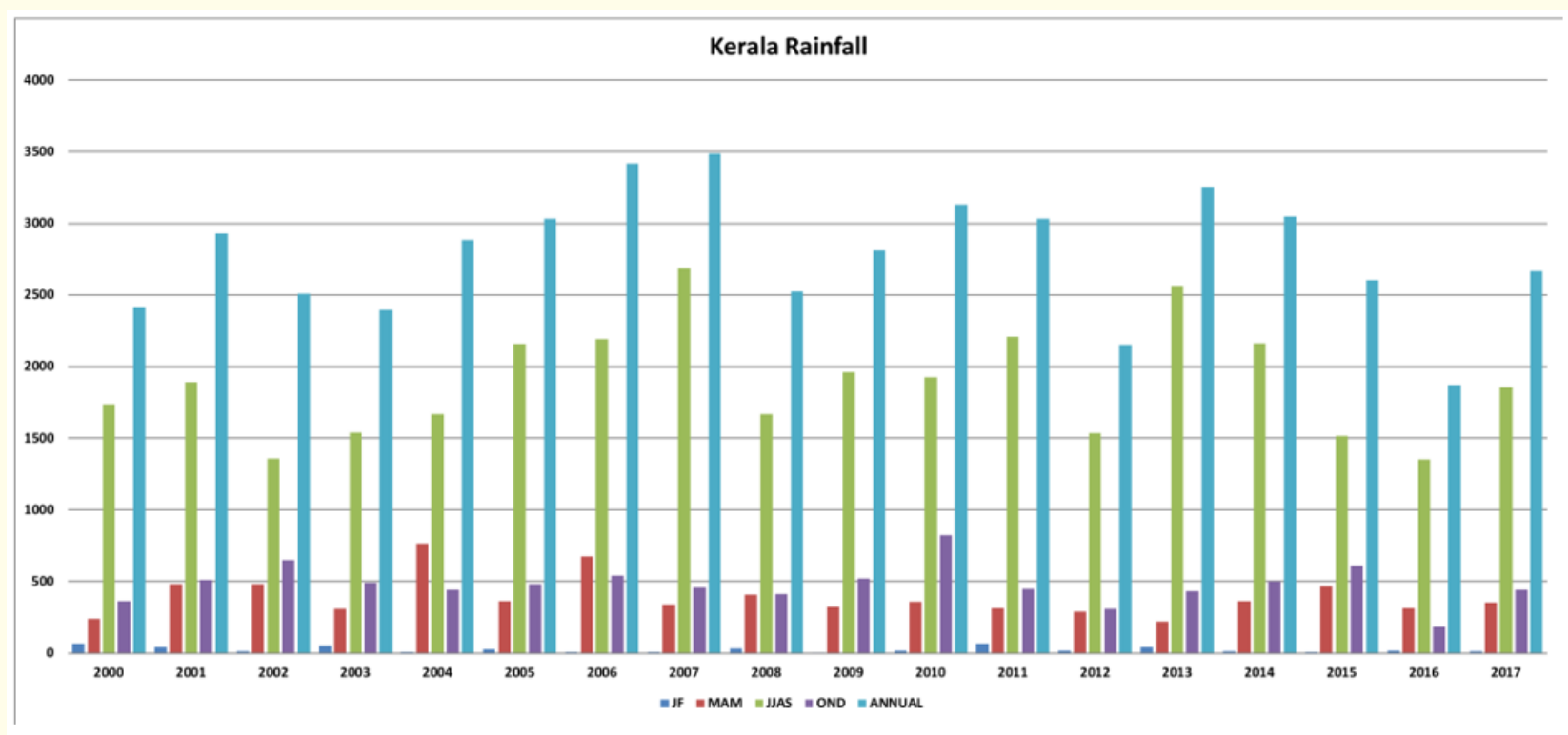

Figure 5: Rainfall data of Kerala, January and February (JF), March, April, May (MAM), June, July, August, September (JJAS), October, November, December (OND). 


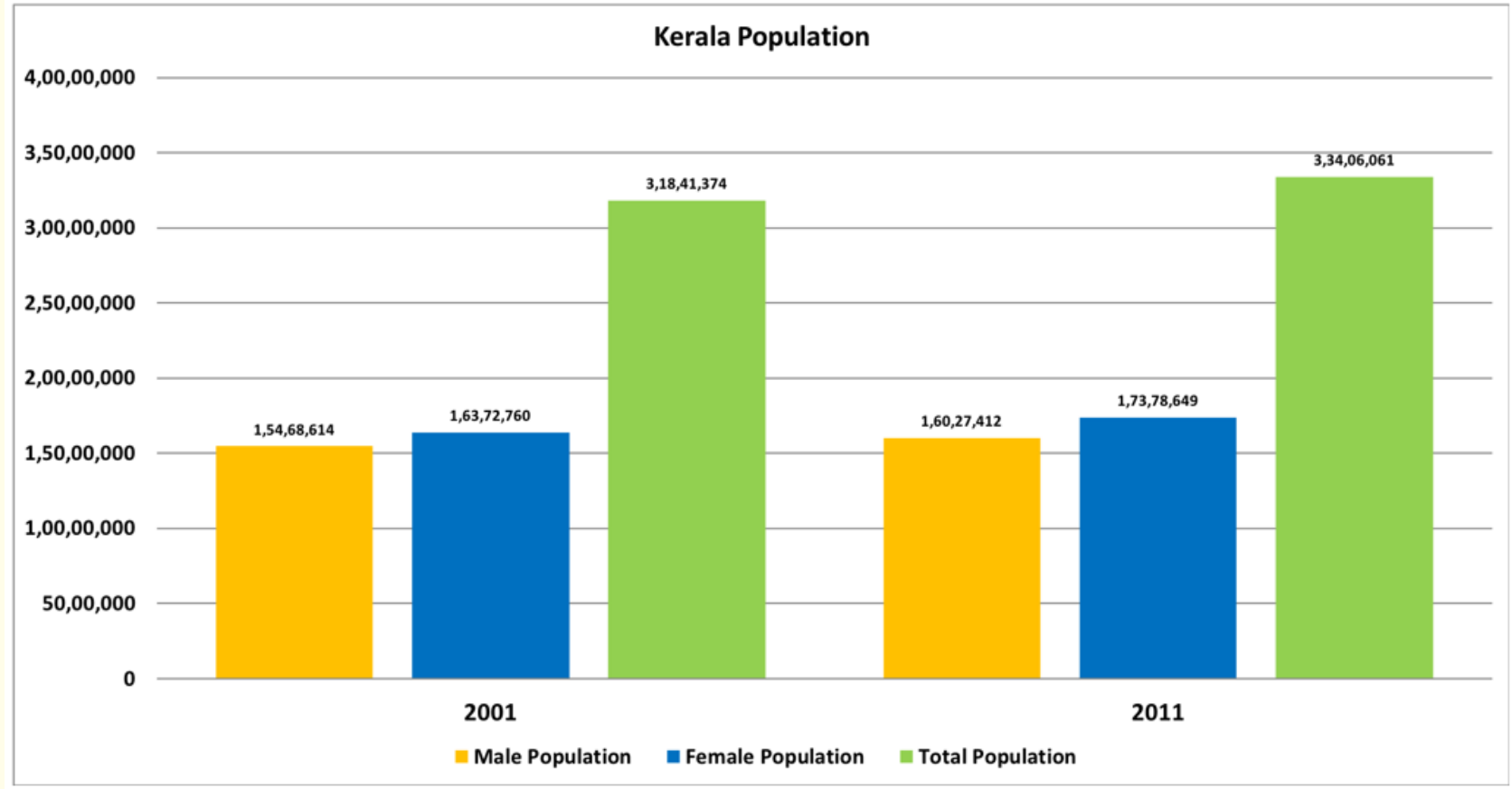

Figure 6: Population of Kerala.

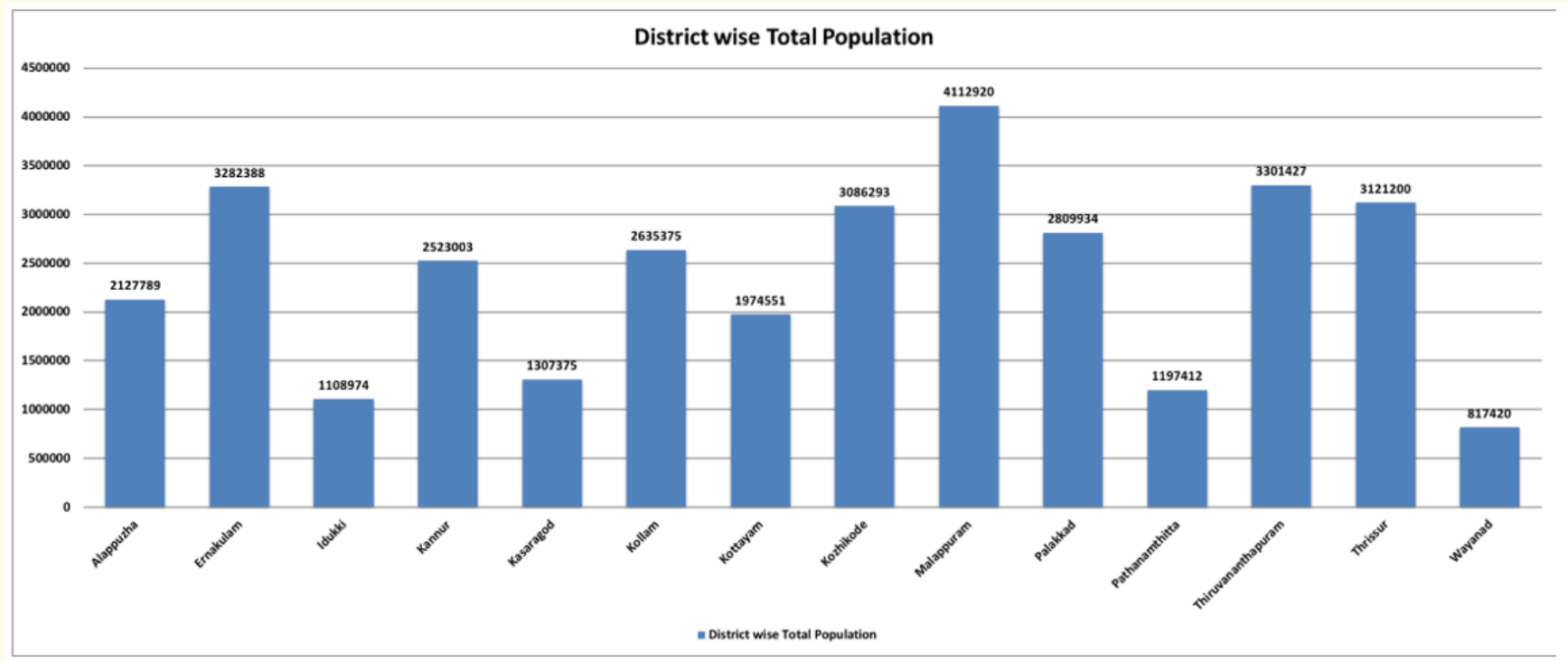

Figure 7: Population of Kerala District wise. 


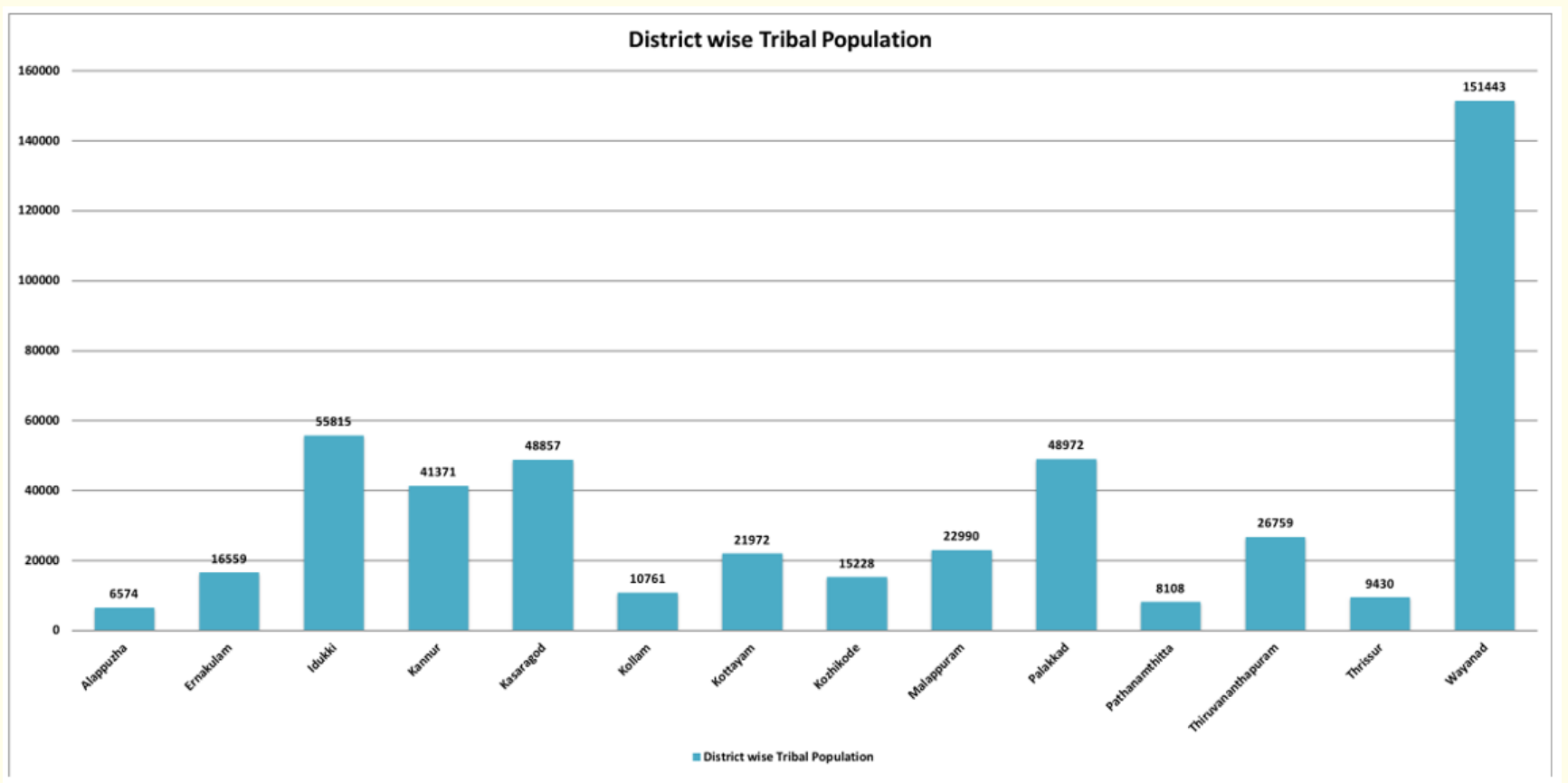

Figure 8: Tribal population of Kerala District wise.

\section{Livestock}

Kerala has a livestock population of approximately 2.73 million as per $19^{\text {th }}$ livestock census 2012 by the Government of India. This is a huge decrease from 3.58 million during the $18^{\text {th }}$ livestock census 2007 report. Cattle population contributes to the highest followed by the goat, buffalo, and pigs. Other animals present in Kerala in a very marginal number are sheep, camel, mules, donkeys, horses and ponies.

The total cattle population of Kerala during the census in 2012 is 1.32 million compared to 1.74 and 2.12 million in 2007 and 2003 respectively. Out of this about 0.07 million are indigenous and 1.25 million are exotic/crossbred (Figure 9 and 10). The total buffalo population is 0.10 million in census 2012 , with 0.03 million females and 0.07 million male population (Figure 11 and 12). A total of about 220 horses and ponies are there in Kerala as per 2012 census consisting of 70 females and 150 males (Figure 13 and 14). A total of 55,780 pigs were recorded during the census 2012 compared to 59,020 during census 2007 . With higher numbers of the population being exotic/crossbred 50,820 to that of indigenous 4,970 (Figure 15 to 17). The total dog population recorded during the census in 2012 is 9,23,360 higher than that of the census in 2007 having only $8,58,620$. Out of which only 2,05,460 are female, while the rest of 7,17,900 are male (Figure 18 and 19).

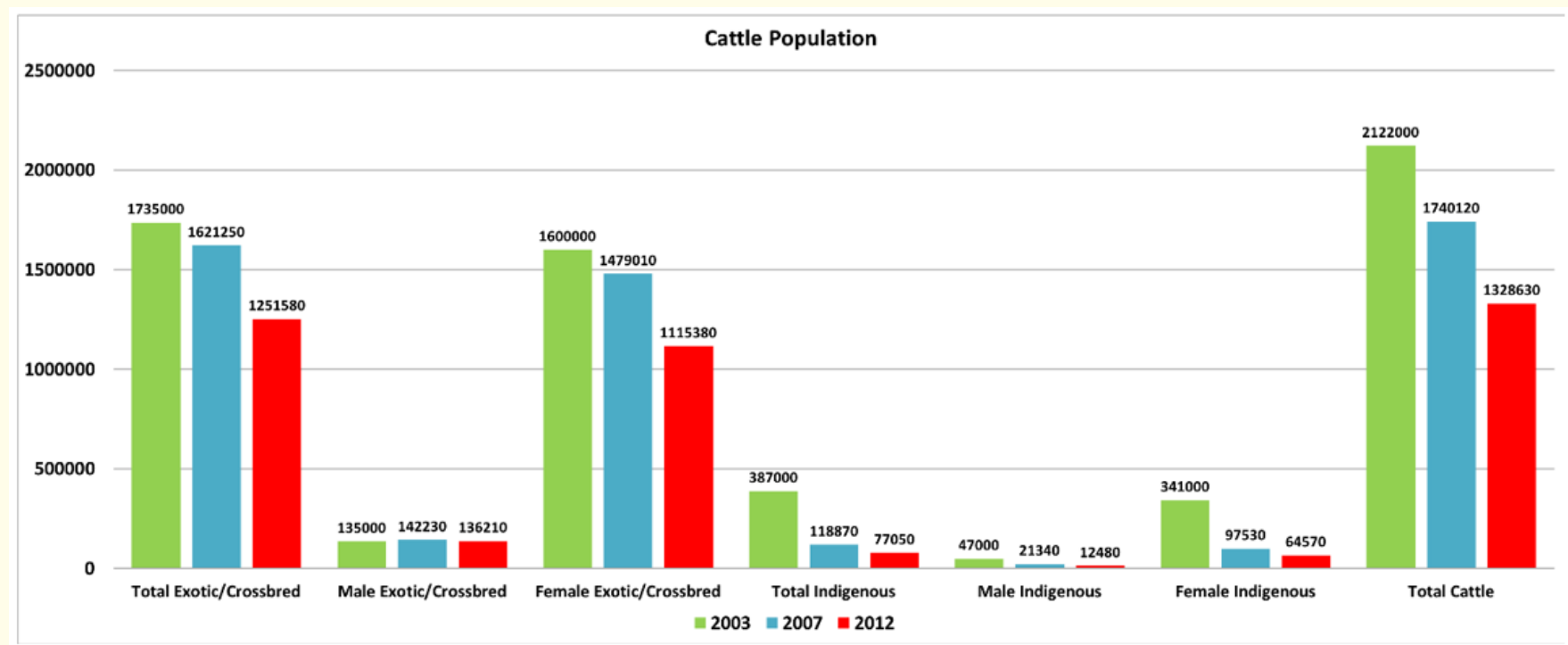

Figure 9: Total cattle population of Kerala. 


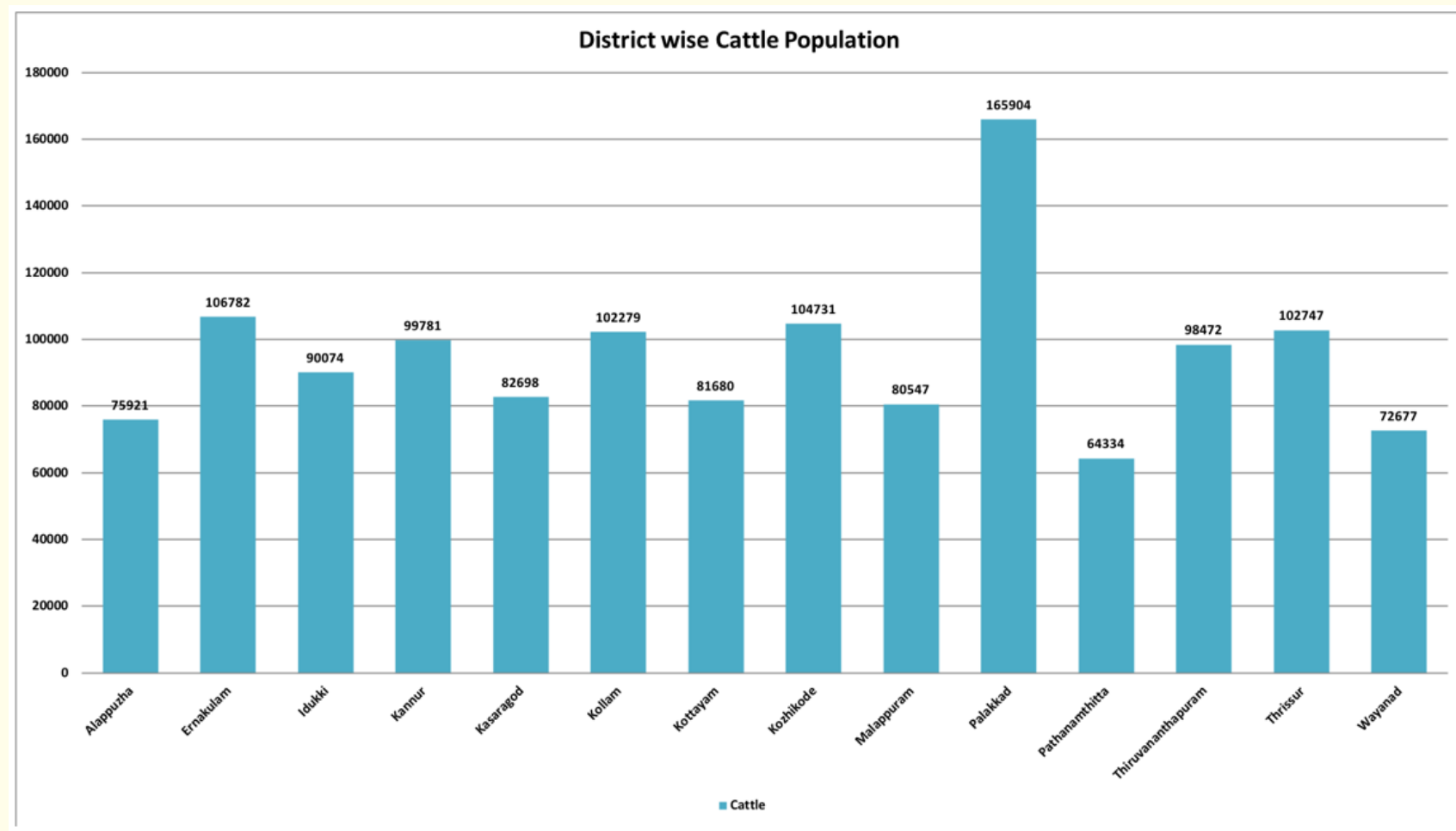

Figure 10: Cattle population of Kerala District wise.

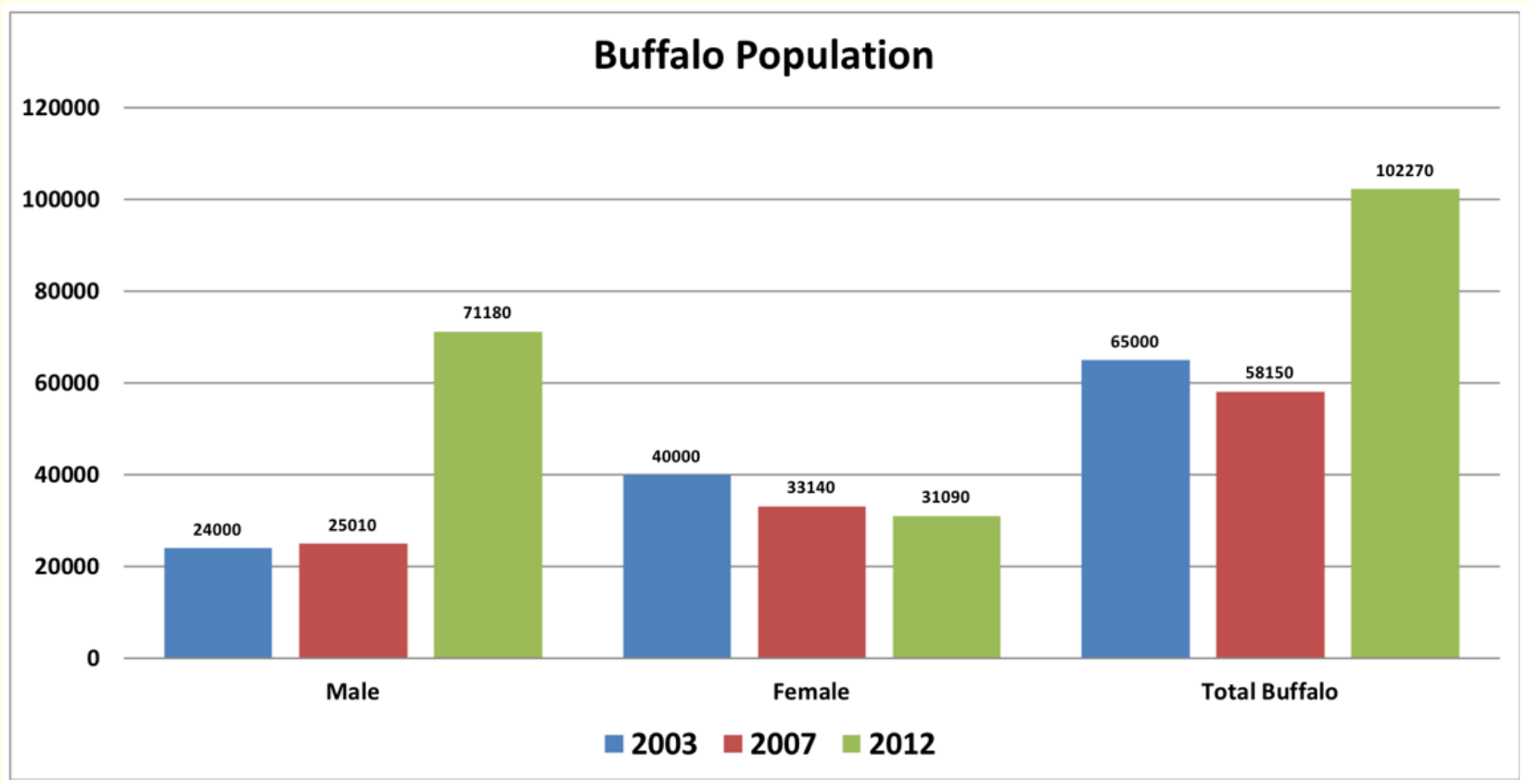

Figure 11: Total buffalo population of Kerala. 


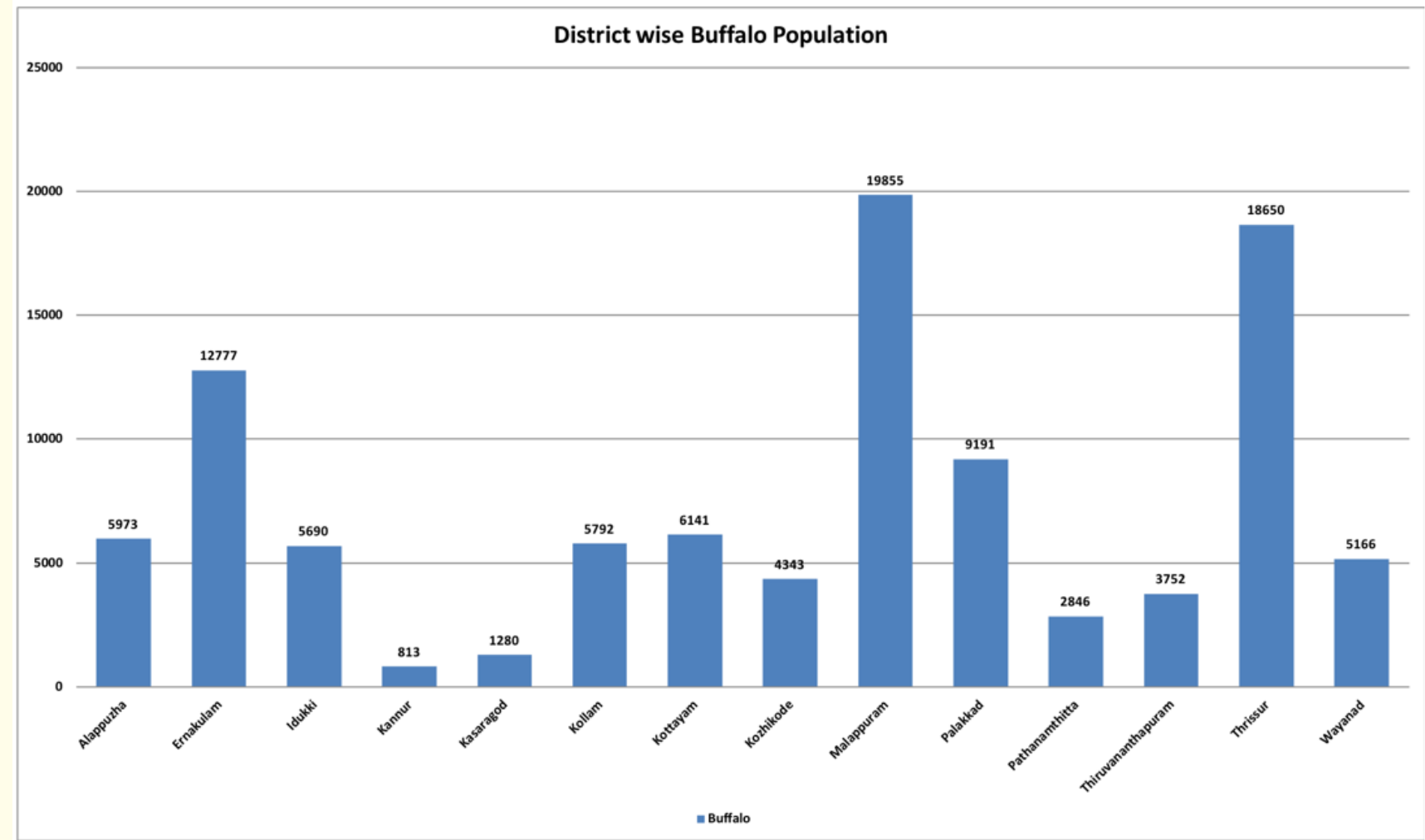

Figure 12: Buffalo population of Kerala District wise.

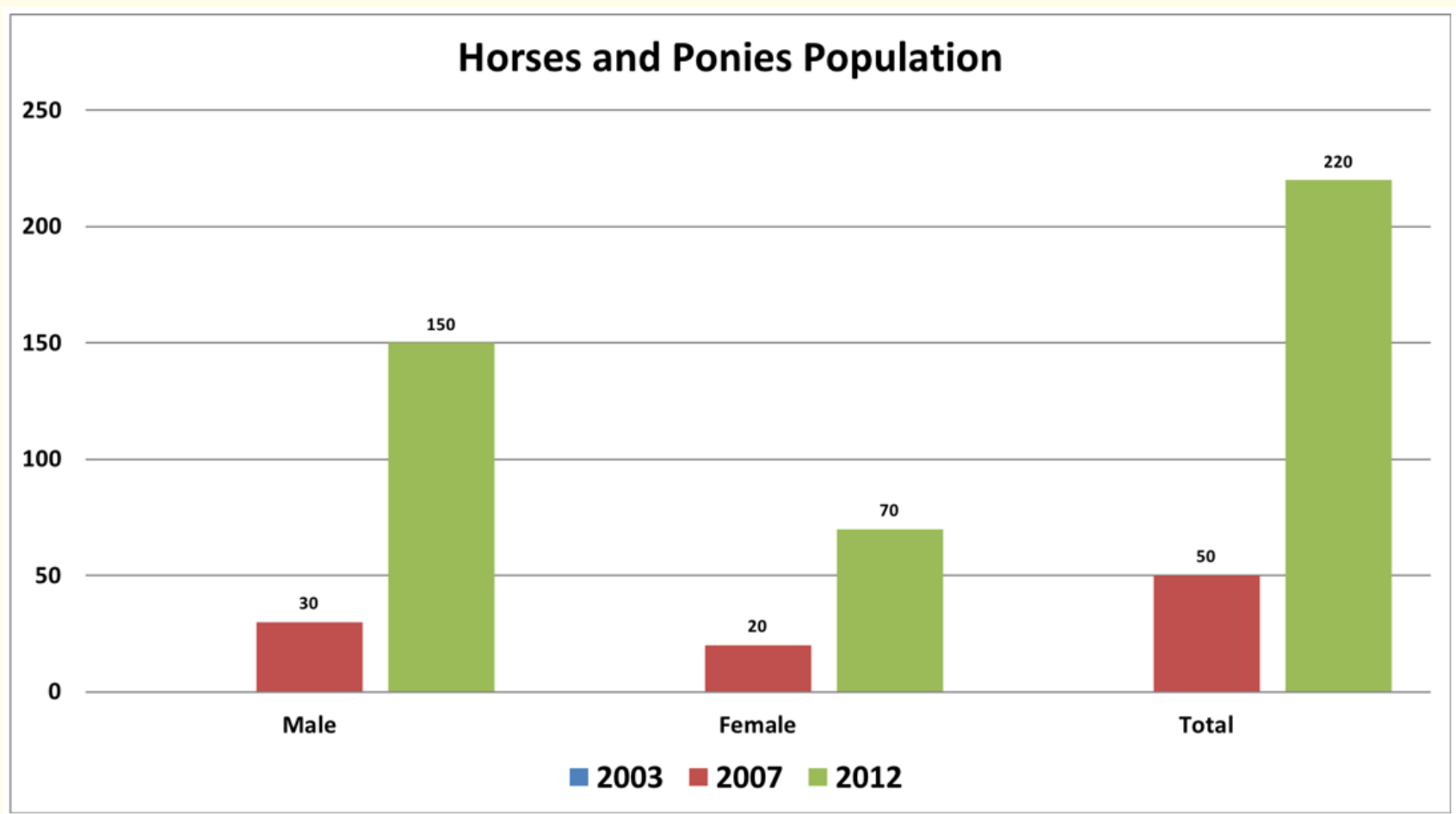

Figure 13: Total horses and ponies population of Kerala. 


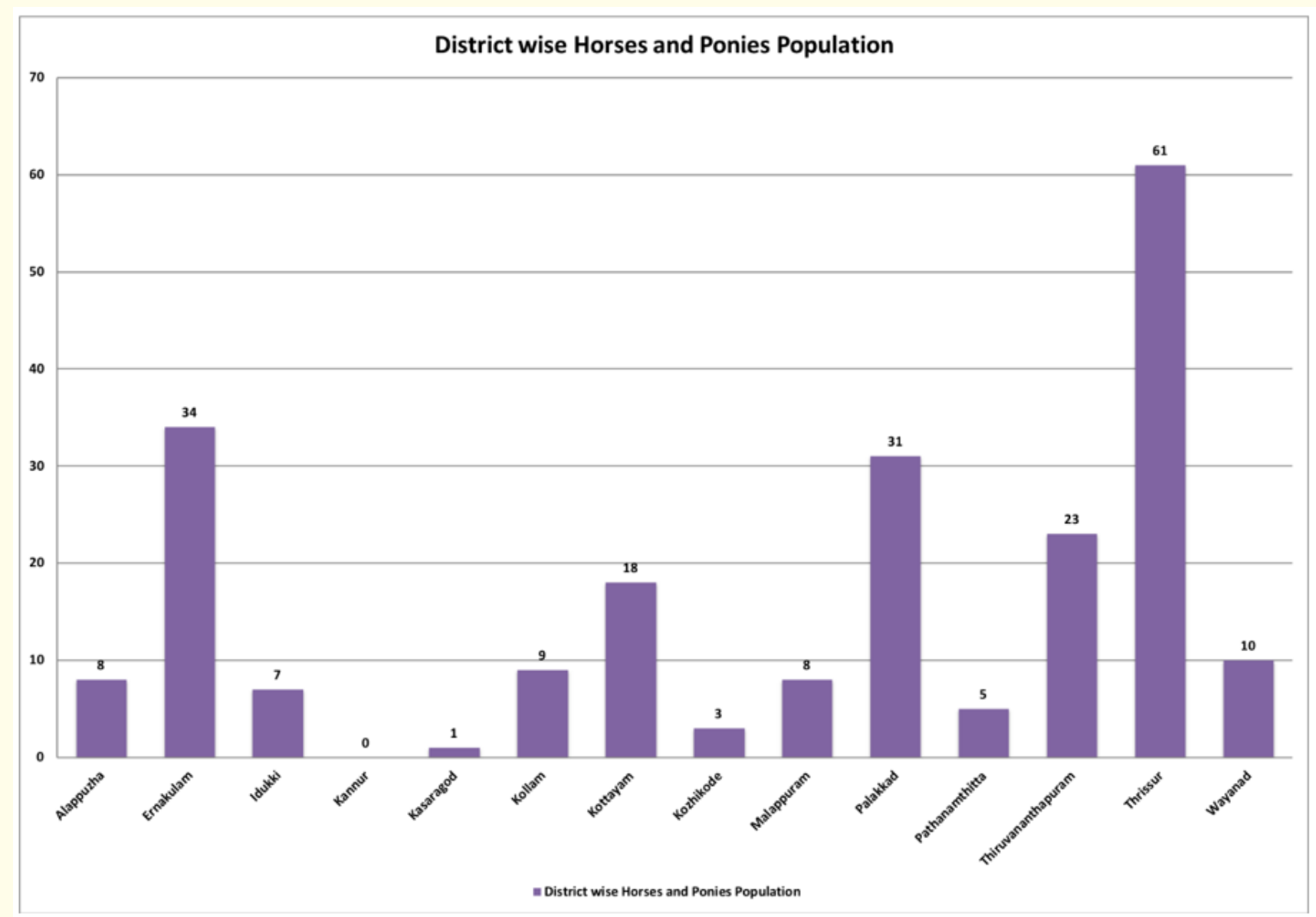

Figure 14: Horses and ponies population of Kerala District wise.

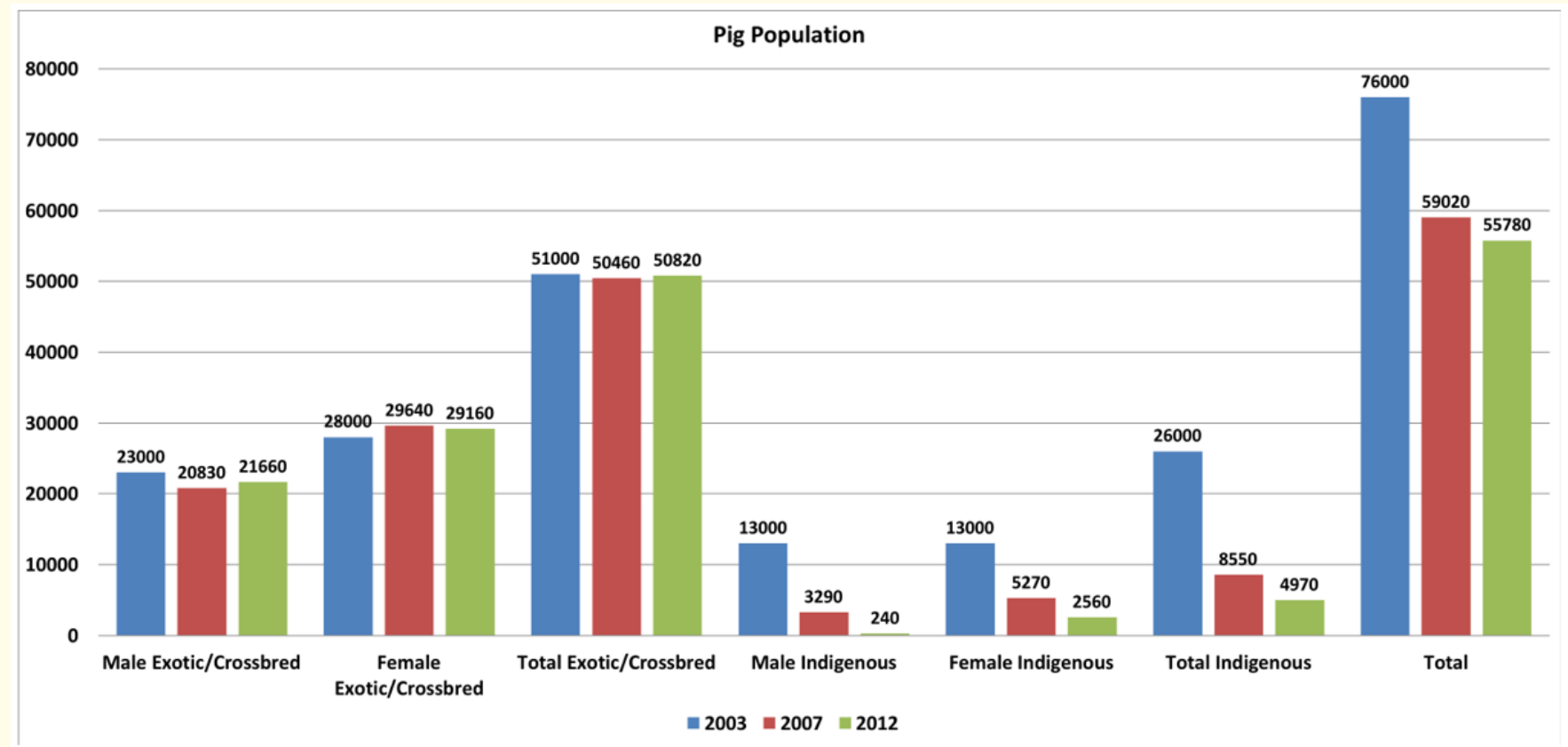

Figure 15: Total pig population of Kerala. 


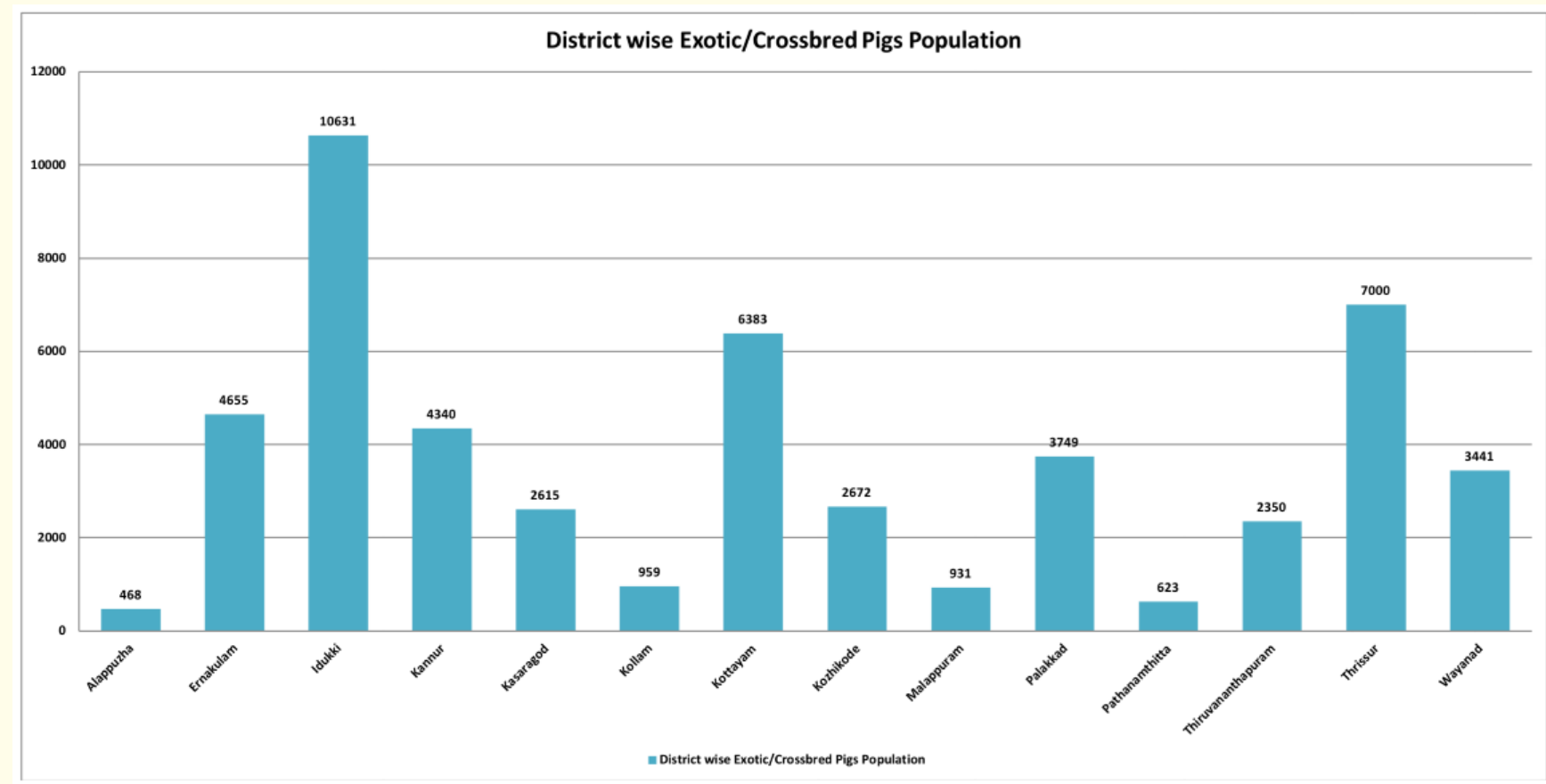

Figure 16: Exotic/crossbred pig population of Kerala District wise.

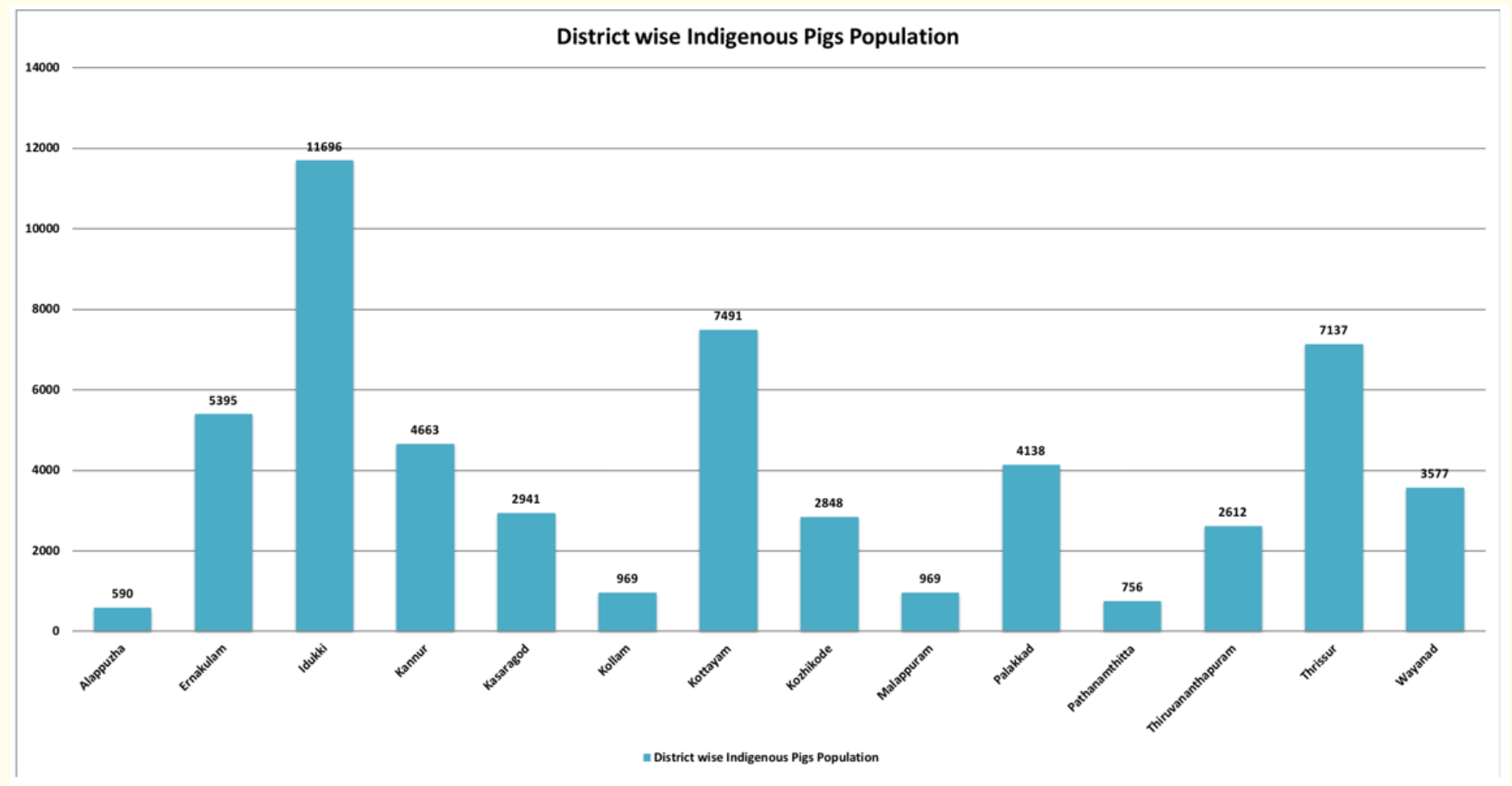

Figure 17: Indigenous pig population of Kerala District wise. 


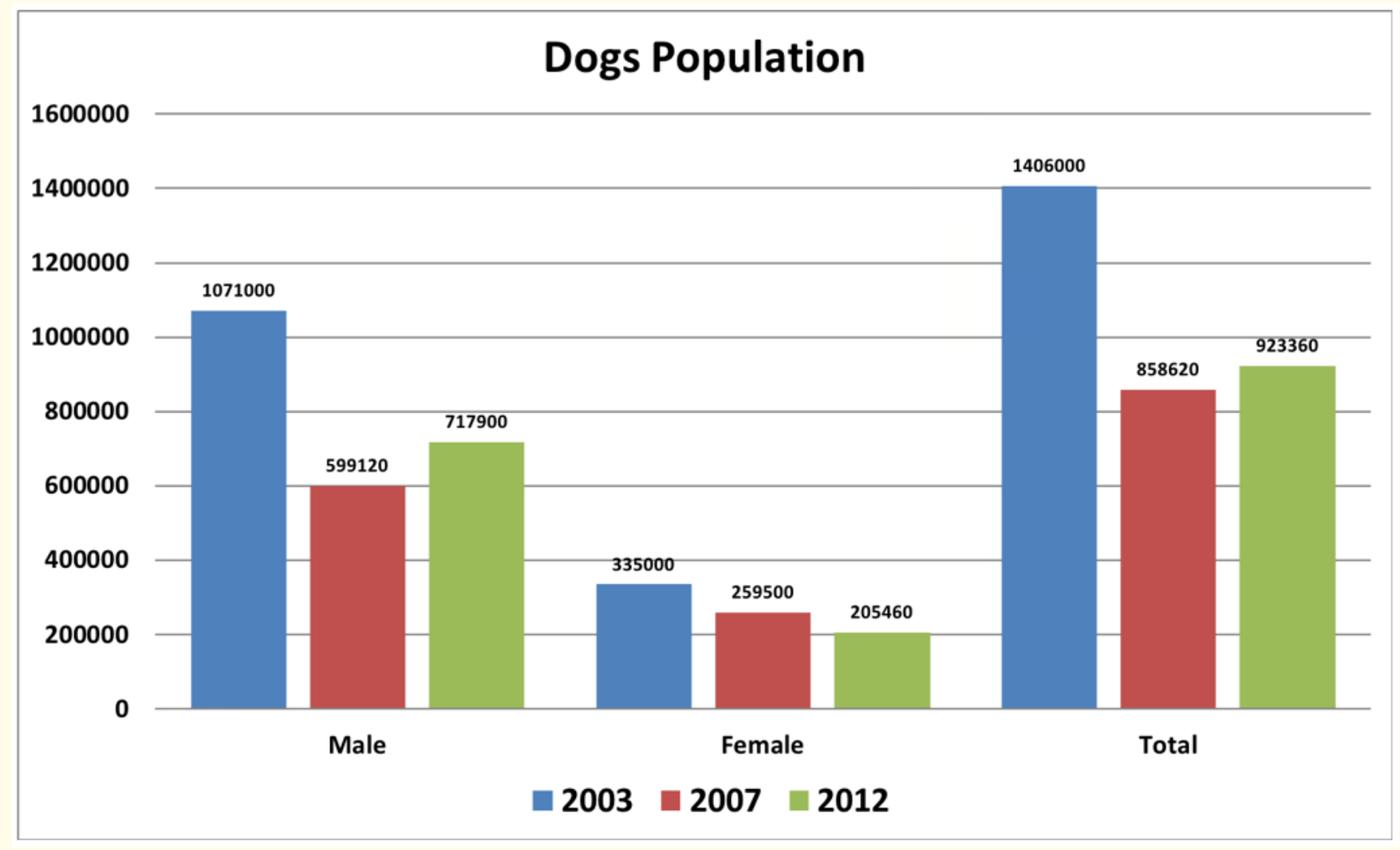

Figure 18: Total dog population of Kerala.

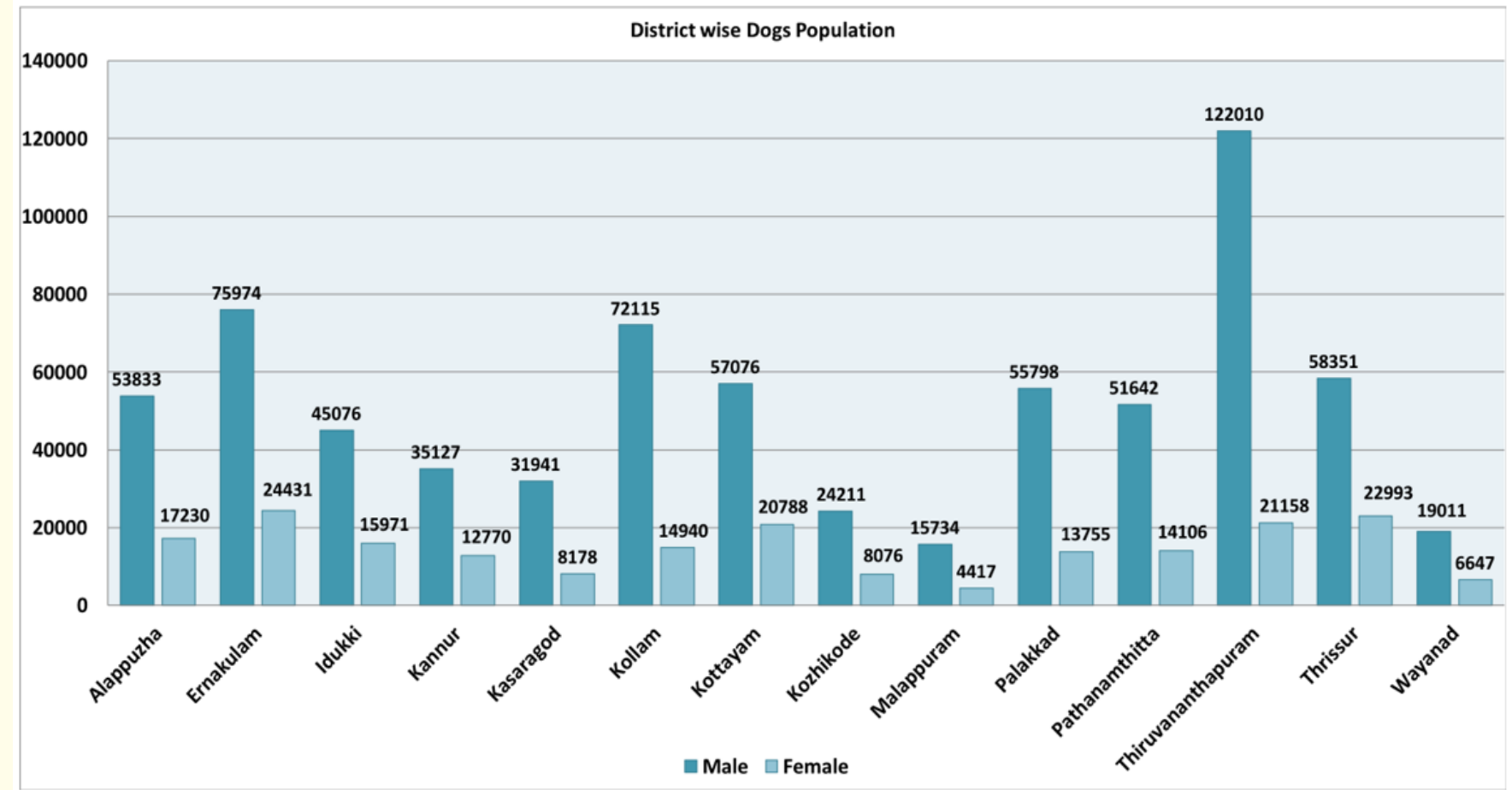

Figure 19: Dog population of Kerala District wise. 
The poultry population of Kerala is massive with 24.28 million during the census in 2012; the largest contributor in poultry is the fowls with 21.71 million populations. From this number, a total of $53,70,215$ hens and 16,03,338 cocks are from backyard poultries. A total of 6,42,511 ducks and 1,93,706 drakes are also maintained in different backyard poultry settings. The same way other birds are also maintained in backyard poultries such as turkeys 51,321, quails $1,31,070$, other poultry birds $3,73,763$ comprising of a total of $1,06,11,984$ poultry birds excluding fowls and ducks in the backyard setting. While in farms/hatcheries a total of 8,52,775 layer, 1,18,37,612 broiler, 7,09,142 ducks and 2,70,415 others birds are maintained based on the data of census in 2012 (Figure 20 to 22).

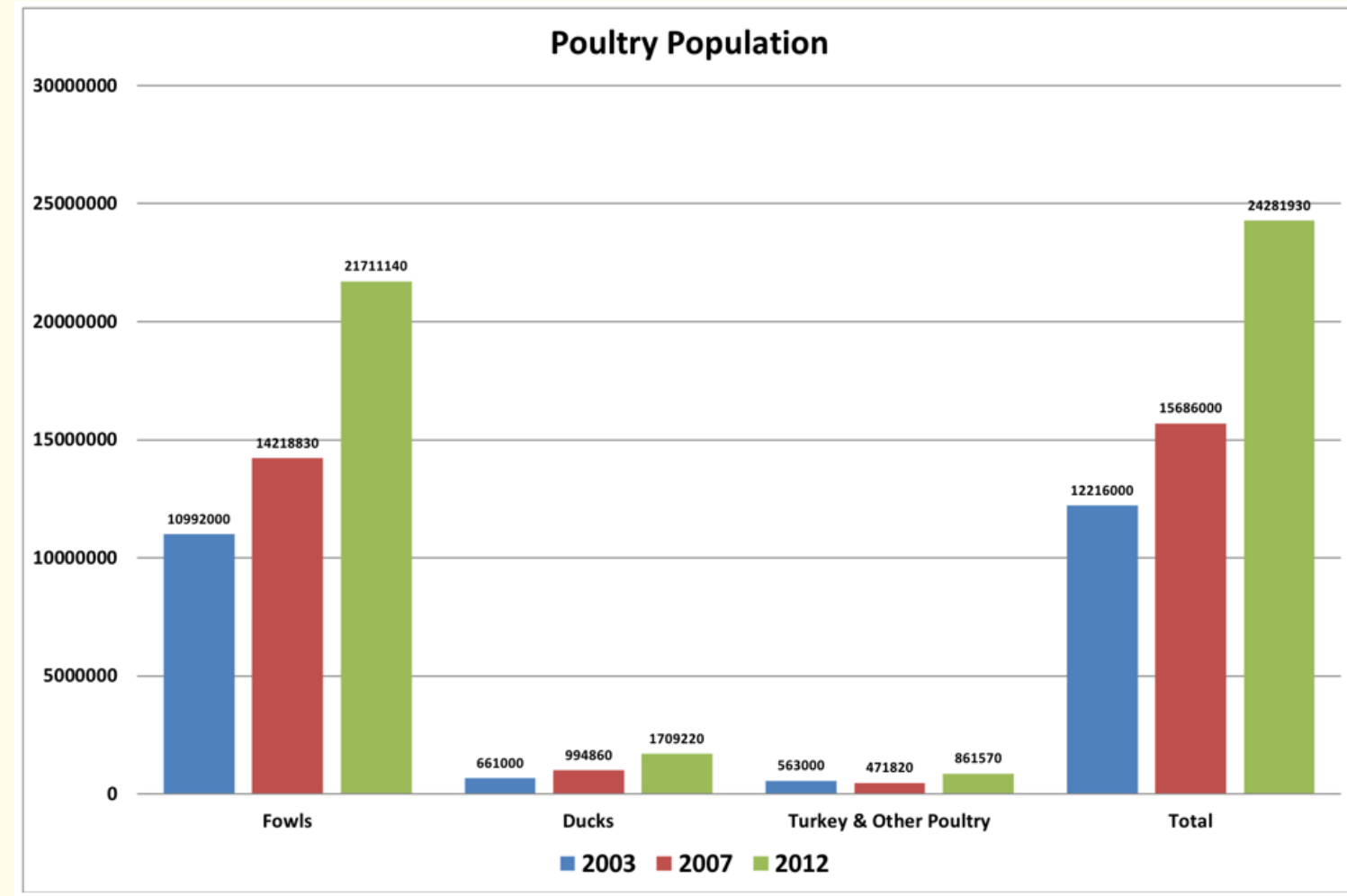

Figure 20: Total poultry population of Kerala.

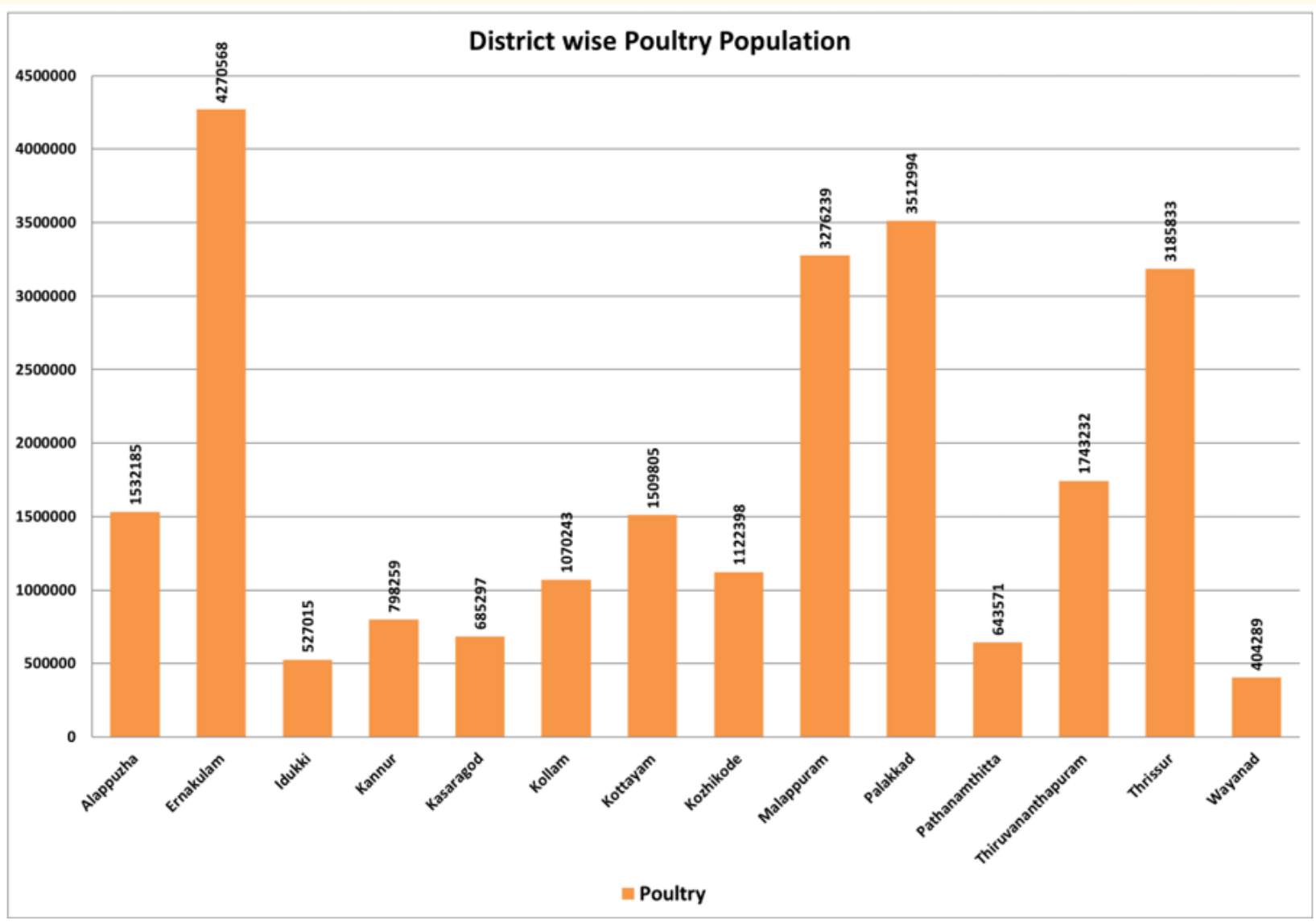

Figure 21: Poultry population of Kerala District wise. 


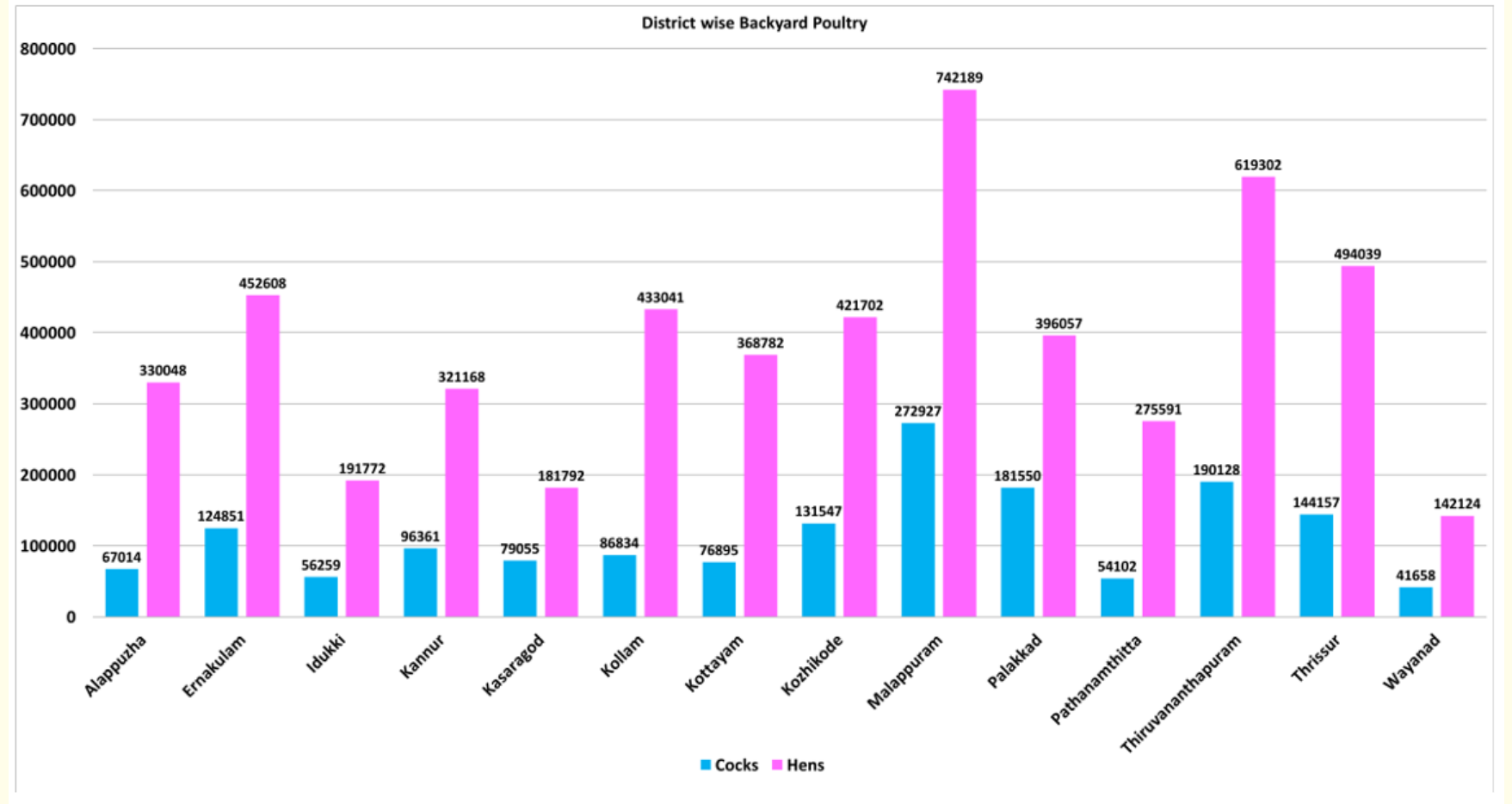

Figure 22: Backyard poultry population of Kerala District wise.

Other than this a total number of 2,63,994 stray dogs and 4,681 stray cattle are also recorded in Kerala.

\section{Forest}

The forest area in Kerala is $11309.4754 \mathrm{KM}^{2}, 29.10 \%$ of the total geographical area of the state. Of this about $81.14 \%(9176.3016$ $\left.\mathrm{KM}^{2}\right)$ is reserved forest, $16.25 \%\left(1837.7957 \mathrm{KM}^{2}\right)$ is a vested forest or EFL (Ecologically Fragile Land), the rest of $2.61 \%$ is proposed reserve forest.

\section{Human influenza}

As per the Kerala health department records during 2009, from the month of August, a total of 1578 cases of influenza H1N1 was reported with 31 deaths. During 2010 of 1534 cases with 90 deaths were reported. In 2011 there were 210 cases with 10 deaths, which went up during 2012 with 623 cases and 14 deaths. 2013 and 2014 saw a reduction of cases in Kerala with 10 cases and 1 death, 62 cases and 1 death respectively. But during 2015 the cases again rose to a total of 928 cases and 76 deaths, followed by 23 cases and 1 death in 2016. In 2017, 1414 cases were reported to the health department with a total of 76 deaths. During 2018
IDSP (Integrated disease surveillance programme) reported a total of 879 cases and 53 deaths. Till the date of $3^{\text {rd }}$ November 2019, a total of 840 cases and 44 deaths were reported. The evolutionary rate of influenza A H1N1 virus from 2009-2017 from Kerala was studied by Jones., et al. and showed that the mean evolutionary rate of the HA and NA is $5.16 \times 10^{-3}$ and $4.27 \times 10^{-3}$ substitution/site/ year, respectively $[39,40]$.

During 2011 an outbreak of H3N2 was reported in the Alappuzha district and a study of influenza samples from Government Medical College, Thiruvananthapuram during October 2010 to December 2016 reported that $26.7 \%$ sample were positive for H3N2 subtype, 10\% were positive for H1N1 2009 pandemic virus and around $6.3 \%$ positive for Influenza B virus. Otherwise, there is not enough data on the occurrence and spread of H3N2 virus from the Kerala State [41].

\section{Avian influenza}

A total of 2.77 lakh birds were culled during outbreaks reported at six epicentres in Kerala from November to December of 2014. 
Later in January 2015 again an outbreak of H5 in the regional poultry farm of Kollam was reported, resulting in the culling of 0.08 lakh birds. During $29^{\text {th }}$ July 2015 India declared itself free of highly pathogenic avian influenza H5 subtype. But after a short period, it re-emerged again with outbreaks that happened in Kerala, as mentioned in table 1 [42].
Low pathogenic H6N2 avian influenza virus (A/duck/ India/11CL01/2014, Kerala14) was isolated from apparently healthy domestic duck from a backyard farm in Pathanamthitta district during November 2014. Using phylogenetic analysis it was identified that this H6N2 virus is closely associated with Asia II Lineage of avian influenza virus [43].

\begin{tabular}{|c|c|c|c|c|c|c|c|c|}
\hline S.No & Year & District & Location & Virus Type & Bird & Cases & Deaths & Destroyed \\
\hline 1 & 2014-15 & Alappuzha & Purakkad \& Thalavady & H5N1 & Ducks & 15000 & 15000 & 213807 \\
\hline 2 & 2014-15 & Kottayam & Parippu Aimananam & H5N1 & Ducks & 500 & 500 & 14584 \\
\hline 3 & 2014-15 & Alappuzha & Chennithala & H5N1 & Ducks & 2554 & 2554 & 135509 \\
\hline 4 & 2014-15 & Kottayam & Vilakkumaram & H5N1 & Ducks & 500 & 500 & 5474 \\
\hline 5 & 2015 & Kollam & Kureepuzha & H5N1 & Turkey & 1628 & 1628 & 6475 \\
\hline 6 & 2016-17 & Alappuzha & Thakazhy & H5N8 & - & 100 & 100 & 14648 \\
\hline 7 & $2016-17$ & Alappuzha & Ramankary & H5N8 & - & 15 & 15 & 6483 \\
\hline 8 & $2016-17$ & Kottayam & Thalayazham & H5N8 & - & 2046 & 2046 & 15262 \\
\hline 9 & 2016-17 & Kottayam & Neendoor & H5N8 & - & 1220 & 1220 & 3020 \\
\hline 10 & $2016-17$ & Kottayam & Paippad & H5N8 & - & 418 & 418 & 20850 \\
\hline 11 & 2016-17 & Alappuzha & Veliyanad & H5N8 & - & 1816 & 1816 & 2807 \\
\hline 12 & 2016-17 & Alappuzha & Cheruthana & H5N8 & - & 8123 & 8123 & 16157 \\
\hline 13 & $2016-17$ & Alappuzha & Neelamperoor & H5N8 & - & 700 & 700 & 10070 \\
\hline 14 & $2016-17$ & Alappuzha & Pallippad & H5N8 & - & 1435 & 1435 & 14305 \\
\hline 15 & $2016-17$ & Kottayam & Arpookara & H5N8 & - & 2506 & 2506 & 25545 \\
\hline 16 & $2016-17$ & Kottayam & Aymanam & H5N8 & - & 6197 & 6197 & 28191 \\
\hline 17 & $2016-17$ & Alappuzha & Nedumudy & H5N8 & - & 10 & 10 & 50661 \\
\hline 18 & $2016-17$ & Alappuzha & Ambalapuzha North & H5N8 & - & 13505 & 13505 & 51509 \\
\hline 19 & $2016-17$ & Alappuzha & Veeyapuram & H5N8 & - & 170 & 170 & 730 \\
\hline 20 & $2016-17$ & Alappuzha & Champakkulam & H5N8 & - & 418 & 418 & 38105 \\
\hline 21 & $2016-17$ & Alappuzha & Edathua & H5N8 & - & 6935 & 6935 & 70304 \\
\hline 22 & $2016-17$ & Alappuzha & Pulincunnu & H5N8 & - & 4500 & 4500 & 23580 \\
\hline 23 & $2016-17$ & Alappuzha & Chennithala & H5N8 & - & 783 & 783 & 168677 \\
\hline 24 & $2016-17$ & Kottayam & Vechur & H5N8 & - & 11009 & 11009 & 27312 \\
\hline 25 & $2016-17$ & Alappuzha & Purakkad & H5N8 & - & 32 & 32 & 10423 \\
\hline 26 & $2016-17$ & Alappuzha & Punnappra South & H5N8 & - & 132 & 132 & 3350 \\
\hline 27 & $2016-17$ & Alappuzha & Thalavady & H5N8 & - & 110 & 110 & 6499 \\
\hline 28 & $2016-17$ & Alappuzha & Karuvatta & H5N8 & - & 880 & 880 & 48882 \\
\hline 29 & $2016-17$ & Alappuzha & Ambalapuzha South & H5N8 & - & 3146 & 3146 & 9480 \\
\hline 30 & 2016-17 & Kottayam & Kumarakom & H5N8 & - & 480 & 480 & 1800 \\
\hline
\end{tabular}

Table 1: Avian Influenza Outbreaks in Kerala reported to the OIE. 


\section{Conclusion}

This uniqueness of the landscape results in making Kerala a place conducive for many zoonotic viruses to thrive and to spillover to humans. The important zoonotic viral diseases of India are Japanese encephalitis virus (JEV), Chikungunya virus, Rabies, Chandipura virus (CHPV), Kyasanur forest disease (KFD), Swine and Avian influenza, Buffalopox virus, Nipah virus, Ganjam disease virus, Bhanja virus. Among these viruses, Swine and Avian influenza, KFD, Nipah, Rabies, Chikungunya virus and JEV are already present either in Kerala (in nature or as infections) or in the neighbouring states. In addition, many bacterial zoonotic diseases of medical importance, such as leptospirosis, brucellosis, bovine tuberculosis, toxoplasmosis, Scrub Typhus are also present in Kerala [44]. The close proximity and easy accessibility of different hosts of the influenza A virus in Kerala is something crucial, as influenza $A$ viruses have the ability to change through mutations and reassortment with other subtypes. The presence of the mixing vessel (pigs) and the birds (wild and domestic) in the vicinity give the opportunity to avian viruses to spread to the pig population and then to humans. There is also the possibility of spread of human influenza viruses from humans to these captive pigs resulting in chances of recombination between human and avian viruses [14]. The influenza viruses can stay stable longer in cold conditions and in saline water [45], conditions that are present in Kerala. Without any surveillance system or preventive measures to curtail the interaction between the captive pigs and wild avian species, outbreaks similar to ones in China and Brazil where novel outbreaks of influenza viruses have happened in the past could occur here as well [46]. The high rainfall and humidity could help the influenza virus spread from an infected host, and low temperature and presence of many different hosts in close vicinity are major points to support the maintenance and widespread dissemination of the virus in the environment. As per the census reports, pigs are distributed throughout the state, along with poultry, (Figure 16, 17 and 21) buffalo and cattle population (Figure 10 to 12), with most of them being backyard farms with multiple types of animals mixed together. The avian influenza outbreaks reported to the OIE are mostly from Alappuzha and Kottayam district, with one report from Kollam district (Table 1). The lack of report from districts such as Ernakulam, Malappuram, Thiruvananthapuram, Palakkad and Thrissur where both hatcheries and backyard poultries are present in high numbers (Figure 21 and 22), indicates the need for proper surveillance and reporting as it is unlikely to be free of infections. It is noteworthy that with a high population of pigs in the state, there is no report or study on the presence of influenza viruses in pigs even from districts such as Idukki, Kottayam and Thrissur which has a very high population of the pigs.
The changes from mutations to reassortments in influenza force the need for a yearly vaccination to protect against viruses. Available antiviral drugs are oseltamivir phosphate (available as a generic version or under the trade name Tamiflu ${ }^{\circledR}$ ), zanamivir (trade name Relenza ${ }^{\circledR}$ ), peramivir (trade name Rapivab ${ }^{\circledR}$ ), and baloxavir marboxil (trade name Xofluza ${ }^{\circledR}$ ) are also approved by different agencies for use [47] in the state. The widely available antiviral drug, oseltamivir phosphate have already thrown up reports of resistance in some countries [48], increasing the fear of losing an important arsenal in the fight against influenza virus, akin to older drugs such as amantadine and rimantadine to which virus is completely resistant. New antiviral drugs from artificial or natural compounds are being extensively research for use in case of an emergency (Pandemic). There have been reports showing the antiviral effects of plant molecules [49], as well as from mushrooms with potent antiviral activities against the influenza viruses [50], but these need to be explored further.

Above points warrant several action plans. There is a need to study the influenza type $B, C$ and D for their distribution in the state, as only Influenza A alone is monitored. Much work has to be done on the surveillance of all the types of influenza viruses from different hosts to get a realistic picture of the status of all influenza viruses in the state. Public and farm labourers who directly interact with these animals must be trained and monitored. There is also a need for regular testing of the farm animals to ensure the health status of such animals and to verify the presence of possible disease spread from either humans or wild animals/birds. There is a need for a plan to limit the mingling of too many subtypes of the virus in very close proximity. The possibility of the emergence of a new type of virus and how the health system will manage such an unprecedented situation needs to be formalised.

\section{Conflict of Interest}

There is no conflict of interest among the authors.

\section{Bibliography}

1. Shaw ML and Palese P. "Orthomyxoviridae". In: Knipe, DM Howley, PM, editors Fields Virology 6th . Wolters Kluwer Health/Lippincott Williams and Wilkins (2013): 1151-1185.

2. Tong S., et al. "New world bats harbor diverse influenza A viruses". PLoS Pathog 9.10 (2013): e1003657.

3. CDC. Flu Symptoms and Complications - CDC (2019).

4. Kilbourne ED. "Influenza pandemics of the 20th century". Emerging Infectious Diseases. Centers for Disease Control and Prevention (CDC) 12 (2006): 9-14. 
5. CDC. Past Pandemics | Pandemic Influenza (Flu) | CDC (2018).

6. Arbeitskreis Blut U “Bewertung BK. Influenza Virus". Transfus Med Hemotherapy 36.1 (2009): 32-39.

7. Di Lella S., et al. "Modulation of the pH Stability of Influenza Virus Hemagglutinin: A Host Cell Adaptation Strategy". Biophysical Journal. Biophysical Society 110 (2016): 2293-301.

8. OIE. What is Avian Influenza: OIE - World Organisation for Animal Health (2019).

9. World Health Organization. Human infection with avian influenza A(H7N9) virus - China (2015).

10. WHO. Cumulative number of confirmed human cases for avian influenza A(H5N1) reported to WHO, 2003-2019 (2019).

11. Shope RE. Swine Influenza: Iii. Filtration Experiments and Etiology". Journal of Experimental Medicine 54.3 (1931): 373-85.

12. OIE. Swine Influenza Aetiology Epidemiology Diagnosis Prevention and Control References (2009).

13. Tu J., et al. "Isolation and molecular characterization of equine H3N8 influenza viruses from pigs in China”. Archives of Virology 154.5 (2009): 887-890.

14. Ma W., et al. "The pig as a mixing vessel for influenza viruses: Human and veterinary implications". Journal of Molecular and Genetic Medicine 03.01 (2009).

15. CDC. Influenza in Cats | Seasonal Influenza (Flu) | CDC (2018).

16. Fiorentini L., et al. "Influenza A pandemic (H1N1) 2009 virus outbreak in a cat colony in Italy". Zoonoses Public Health 58.8 (2011): 573-581.

17. Hatta M., et al. "Characterization of a feline influenza A(H7N2) virus”. Emerging Infectious Diseases 24.1 (2018): 75-86.

18. CDC. Key Facts about Canine Influenza (Dog Flu) | Seasonal Influenza (Flu) | CDC (2018).

19. Zhu H., et al. "Origins and Evolutionary Dynamics of H3N2 Canine Influenza Virus”. Journal of Virology 89.10 (2015): 54065418.

20. Voorhees IEH., et al. "Spread of canine influenza a(H3N2) virus, United States". Emerging Infectious Diseases 23.12 (2017): 1950-1957.

21. Crawford PC., et al. "Epidemiology: Transmission of equine influenza virus to dogs”. Science 310.5747 (2005): 482-485.

22. Singh RK., et al. "A comprehensive review on equine influenza virus: Etiology, epidemiology, pathobiology, advances in developing diagnostics, vaccines, and control strategies. Frontiers in Microbiology". Frontiers Media S.A. 9 (2018).
23. Reperant LA., et al. "Avian influenza viruses in mammals". OIE Revue Scientifique et Technique 28.1 (2009): 137-159.

24. Shin DL., et al. "Highly pathogenic avian influenza A(H5N8) virus in gray seals, Baltic Sea". Emerging Infectious Diseases 25.12 (2019): 2295-2298.

25. Campos ACA., et al. "Bat influenza a(HL18NL11) virus in fruit bats, Brazil”. Emerging Infectious Diseases 25.2 (2019): 333337.

26. Alghamdi A., et al. "Molecular Evidence of Influenza A Virus Circulation in African Dromedary Camels Imported to Saudi Arabia, 2017-2018". Open Forum Infectious Diseases 6.10 (2019).

27. Murakami S., et al. "Influenza D virus infection in dromedary camels, Ethiopia. Vol. 25, Emerging Infectious Diseases”. Centres for Disease Control and Prevention (CDC) (2019): 12241225.

28. Sreenivasan CC., et al. "Influenza a in bovine species: A narrative literature review. Viruses. MDPI AG 11 (2019).

29. O'Donovan T., et al. "Seroprevalence of influenza D virus in selected sample groups of Irish cattle, sheep and pigs". Irish Veterinary Journal 72.1 (2019).

30. Quast M., et al. "Serological evidence for the presence of influenza D virus in small ruminants". Veterinary Microbiology 180.3-4 (2015): 281-285.

31. Lvov DK., et al. "Comparison of influenza viruses isolated from man and from whales". Bull World Bulletin of the World Health Organization 56.6 (1978): 923-930.

32. Hinshaw VS., et al. "Characterization of two influenza A viruses from a pilot whale”. Journal of Virology 58.2 (1986): 655-656.

33. Hall JS., et al. "Influenza infection in wild raccoons". Emerging Infectious Diseases 14.12 (2008): 1842-1848.

34. Horimoto T., et al. "Highly pathogenic avian influenza virus infection in feral Raccoons, Japan". Emerging Infectious Diseases 17.4 (2011): 714-717.

35. Li D., et al. "Influenza A(H1N1) pdm09 virus infection in giant pandas, China”. Emerging Infectious Diseases 20.3 (2014): 480-483.

36. Martelli P., et al. "Influenza A(H1N1) pdm09 virus infection in a Captive Giant Panda, Hong Kong". Emerging Infectious Diseases 25.12 (2019): 2303-2306.

37. Boedeker NC., et al. "Pandemic (H1N1) 2009 influenza A virus infection associated with respiratory signs in sloth bears (Melursus ursinus)". Zoonoses Public Health 64.7 (2017): 566-571. 
38. Kerala | History, Map, Capital, and Facts | Britannica (2019).

39. Jones S., et al. "Evolutionary, genetic, structural characterization and its functional implications for the influenza A (H1N1) infection outbreak in India from 2009 to 2017". Scientific Reports 9.1 (2017): 14690.

40. NCDC. State/UT - wise, Year-wise number of cases and deaths from 2012-2019: Ministry of Health and Family Welfare (2019).

41. Dayakar S., et al. "Comparative Study of Molecular Approaches for the Detection of Influenza Virus from Patient Samples Using Real-time PCR: Prospective Disease Burden Study in Kerala (India) from 2010 to 2016". Current Infectious Disease Reports 20.8 (2018): 24.

42. OIE - World Organisation for Animal Health (2020).

43. Kumar M., et al. "Emergence of novel reassortant H6N2 avian influenza viruses in ducks in India". Infection, Genetics and Evolution 61 (2018): 20-23.

44. Dubal ZB., et al. "Important Zoonotic Diseases: Prevention and Control Technical Bulletin ICAR Research Complex for Goa (Indian Council of Agricultural Research), Old Goa- 403 402, Goa, India 39 (2014).

45. Kormuth KA., et al. "Environmental Persistence of Influenza Viruses Is Dependent upon Virus Type and Host Origin. Lowen AC, editor". mSphere 4.4 (2019).

46. Wang C., et al. "Novel human H7N9 influenza virus in China". Integrative Zoology 9.3 (2014): 372-375.

47. CDC. What You Should Know About Flu Antiviral Drugs | CDC (2019).

48. Hurt AC., et al. "Community Transmission of Oseltamivir-Resistant A(H1N1) pdm09 Influenza". N The New England Journal of Medicine 365.26 (2011): 2541-2542.

49. Akram M., et al. "Antiviral potential of medicinal plants against HIV, HSV, influenza, hepatitis, and coxsackievirus: A systematic review". Phyther Research 32.5 (2018): 811-822.

50. Pradeep P., et al. "Antiviral Potency of Mushroom Constituents". In: Medicinal Mushrooms. Singapore: Springer Singapore (2019): 275-297.

\section{Assets from publication with us}

- Prompt Acknowledgement after receiving the article

- Thorough Double blinded peer review

- Rapid Publication

- Issue of Publication Certificate

- High visibility of your Published work

Website: https://www.actascientific.com/

Submit Article: https://www.actascientific.com/submission.php

Email us: editor@actascientific.com

Contact us: +919182824667 